\title{
Managing disorders of consciousness: the role of electroencephalography
}

\author{
Yang Bai ${ }^{1,2,3} \cdot$ Yajun Lin ${ }^{1}$. Ulf Ziemann ${ }^{2,3}$ (D)
}

Received: 10 June 2020 / Revised: 18 July 2020 / Accepted: 18 July 2020 / Published online: 11 September 2020

(c) The Author(s) 2020

\begin{abstract}
Disorders of consciousness (DOC) are an important but still underexplored entity in neurology. Novel electroencephalography (EEG) measures are currently being employed for improving diagnostic classification, estimating prognosis and supporting medicolegal decision-making in DOC patients. However, complex recording protocols, a confusing variety of EEG measures, and complicated analysis algorithms create roadblocks against broad application. We conducted a systematic review based on English-language studies in PubMed, Medline and Web of Science databases. The review structures the available knowledge based on EEG measures and analysis principles, and aims at promoting its translation into clinical management of DOC patients.
\end{abstract}

Keywords Disorders of consciousness · Electroencephalography $\cdot$ Minimally conscious state $\cdot$ Vegetative state Unresponsive wakefulness state $\cdot$ Event-related potential $\cdot$ TMS-EEG

\section{Introduction}

A disorder of consciousness (DOC) is an altered consciousness state generally caused by injury or dysfunction of the neural systems regulating arousal and awareness $[1,2]$. When patients fall into coma after brain injury, they show an absence both of arousal (i.e., eye opening even when stimulated) and awareness (unaware of themselves and the environment) [3]. After the transition from coma, some patients remain unresponsive to external stimulation (or only show simple reflex movements that are uncorrelated with command), and they will be diagnosed as being in a vegetative state/unresponsive wakefulness syndrome (VS/UWS) [4]. Moreover, patients who show fluctuating but definite behavioral evidence of self or environmental awareness can be diagnosed as in minimally conscious state (MCS) [5]. The current 'gold standard' for establishing a diagnosis of VS/

Ulf Ziemann

ulf.ziemann@uni-tuebingen.de

1 International Vegetative State and Consciousness Science Institute, Hangzhou Normal University, Hangzhou, China

2 Department of Neurology and Stroke, University of Tübingen, Hoppe-Seyler-Str. 3, 72076 Tübingen, Germany

3 Hertie Institute for Clinical Brain Research, University of Tübingen, 72076 Tübingen, Germany
UWS or MCS is still behavioral scales like the JFK Coma Recovery Scale-Revised (CRS-R) [6]. However, it is well accepted that this scale has significant limitations [7]. Due to fluctuations of consciousness and fatiguability of the patients and subjective interpretation, assessments based exclusively on behavioral scales can lead to misdiagnosis rate as high as $40 \%$ [8].

Clinicians and neuroscientists now increasingly often seek to obtain information of brain function from neuroimaging or electrophysiological measurements for a more precise assessment of DOC patients. Compared with neuroimaging techniques, electroencephalogram (EEG) recordings are a more widely applicable, less expensive, and more practical technique for application in DOC patients. Many EEG studies in DOC patients have been conducted already and provided valuable information for clinicians to improve the diagnosis, monitoring and prognosis of these patients. However, the EEG paradigms, analysis algorithms and feature extraction are complex. Many EEG-based characteristics have been proposed to describe the pathophysiology underlying DOCs. They have enriched clinical methods for DOC assessment, but at the same time, they have confused clinicians when it comes to selecting the appropriate ones in practice. The purpose of this systematic review is to classify the EEG literature in DOC patients according to protocols, analysis methods and clinical utility. 


\section{Literature sources}

English-language articles were searched in PubMed, Medline and Web of Science databases published up to 15 May 2020. Key search terms were "disorders of consciousness; vegetative state; unresponsive wakefulness syndrome and minimally conscious state' combined with 'electroencephalogram; event-related potentials; brain-computer interfaces; sleep; EEG reactivity; TMS-EEG'. A total of 753 articles were identified. Title and abstract of the retrieved articles were then screened for the following inclusion criteria: (1) original peer-reviewed article; (2) subjects diagnosed as DOC; (3) application of EEG measurement and analysis. Exclusion criteria were: (1) review and guideline articles, and conference proceedings and abstracts; (2) studies on children, acute comatose state, or without explicit EEG results. The retained 119 articles provide the basis for this review and were classified according to EEG measures, paradigms, analysis methods and clinical utility.

\section{Results}

EEG measurements include spontaneous (resting-state EEG: Tables 1, 2, 3, and sleep EEG: Table 4) and evoked EEG (event-related potentials, brain-computer interfaces: Table 5, EEG-reactivity and transcranial magnetic stimulation evoked EEG responses: Table 6). The different paradigms, EEG characteristics and their potential clinical utility are summarized in Fig. 1.

\section{Spontaneous electroencephalogram}

\section{Resting state}

\section{Spectral power}

Spontaneous EEG oscillations can be divided into several frequency bands, which are generally as follows: delta $(1.5-3.5 \mathrm{~Hz})$, theta $(3.5-7.5 \mathrm{~Hz})$, alpha $(7.5-12.5 \mathrm{~Hz})$, beta $(12.5-30 \mathrm{~Hz})$ and gamma $(>30 \mathrm{~Hz})$, according to their specific roles in different brain functions $[9,10]$. The power of these frequency bands is typically highly abnormal in DOC patients (Table 1). Enhanced delta and suppressed alpha activities have been the highlighted markers of low consciousness level [11]. The delta power in DOC patients is higher than in healthy controls (HC) $[12,13]$, and in MCS patients [14]. Spectral power is dominated by the delta band in nearly $80 \%$ of VS/UWS patients $[15,16]$. In addition, power in the theta band is increased in VS/UWS patients compared with HC [12] and in MCS patients compared with $\mathrm{HC}$ or conscious patients [17]. However, MCS patients show higher theta power compared with VS/UWS patients [14].

The depression of alpha power in VS/UWS patients is much stronger than in MCS patients [18]. The alpha power in MCS patients is significantly higher than in VS/UWS patients [19, 20], sometimes even twice as high [15]. Alpha power is higher in the central, parietal and occipital regions in MCS patients compared with VS/UWS patients $[11,18]$. Residual consciousness of DOC patients tightly correlates with alpha power in the frontal and parietal networks [16, 21]. Furthermore, increase of alpha power over time is associated with the chance of consciousness recovery $[19,22$, 23].

High-frequency bands (beta and gamma) have been rarely considered in DOC studies. One study found significantly higher low beta (12-17.75 Hz) power in MCS compared with VS/UWS [14], but in the whole beta band, normalized beta power does not discriminate between MCS and VS/ UWS [13]. Gamma power in DOC patients is lower than in HC [18]. Gamma activity has a critical role in assessing DOC patients' responses to specific brain stimulation: transcranial alternating current stimulation [24], transcranial direct current stimulation [25] and spinal cord stimulation [26] can all significantly increase gamma power.

Quantified indexes based on spectral power in more than one frequency band are often used for diagnosis, treatment monitoring and outcome prediction of DOC patients. Ratios between lower frequencies (delta and theta) and higher frequencies (alpha and beta) show close association with regional glucose metabolism in MCS but not VS/UWS [27]. Moreover, there is a positive correlation between the power ratio (above 8 to below $8 \mathrm{~Hz}$ ) and the CRS-R score, and the peak frequency of the spectrum is also strongly related to the CRS-R score [12].

\section{Non-linear dynamics}

Non-linearity in the time domain In time domain analyses, VS/UWS patients always show the lowest EEG complexity, while MCS patients have higher but still moderately lower complexity than HC [28]. Approximate entropy (ApEn) is one of the frequently used non-linear indices for capturing consciousness-related EEG complexity. The ApEn values of VS/UWS patients are commonly lower than in HC (sensitivity: 95\%, specificity: 100\%) [29]. ApEn values in VS/UWS are also lower than in MCS over a broad frequency band [19], which is consistent with the Lempel-Ziv complexity analysis [28]. In addition, ApEn and Lempel-Ziv complexity are closely associated with outcome [28]. Most patients with the lowest ApEn values die or remain in persistent 
Table 1 EEG spectral power measurements in disorders of consciousness

\begin{tabular}{|c|c|c|c|c|}
\hline Clinical application & Literature & Frequency bands & Subjects (numbers) & Main findings \\
\hline \multirow[t]{2}{*}{ Diagnosis } & Coleman et al. [27] & $\begin{array}{l}\text { Ratio between lower frequencies } \\
\text { (delta and theta) and higher } \\
\text { frequencies (alpha and beta) }\end{array}$ & $\begin{array}{l}\text { MCS } 4 \\
\text { VS/UWS } 6\end{array}$ & $\begin{array}{l}\text { Correlation between EEG power } \\
\text { ratio index and regional glucose } \\
\text { metabolism was preserved in all } \\
\text { MCS, but was absent in all VS/ } \\
\text { UWS } \\
\text { VS/UWS showed a significantly } \\
\text { higher EEG power ratio index in } \\
\text { comparison with the MCS }\end{array}$ \\
\hline & Leon-Carrion et al. [17] & Delta and theta & $\begin{array}{l}\text { SND } 9 \\
\text { MCS } 7\end{array}$ & $\begin{array}{l}\text { Posterior sources of delta and theta } \\
\text { frequencies had higher amplitude } \\
\text { in MCS patients than in SND } \\
\text { patients }\end{array}$ \\
\hline
\end{tabular}

$\begin{array}{lll}\text { Babiloni et al. [117] } & \text { Delta and alpha } 13\end{array}$

Lehembre et al. [20]

Delta and alpha

Lechinger et al. [12]

Delta, theta, alpha and ratio

Sitt et al. [13]

Chennu et al. [16]

Delta and alpha

Rossi Sebastiano et al. [11] Delta and alpha

Piarulli et al. [14]
Delta, theta and alpha
LIS 13

MCS 18

VS/UWS 10

$\mathrm{HC} 14$

MCS 9

VS 8

Power of alpha2 (individual alpha frequency -2 to individual alpha frequency) and alpha3 (individual alpha frequency to individual alpha frequency +2 ) in all regions was lower in patients with LIS compared to $\mathrm{HC}$

The power of delta in central, parietal, occipital and temporal regions was higher in patients with LIS compared to $\mathrm{HC}$

VS/UWS showed increased delta power but decreased alpha power compared with MCS

VS/UWS showed higher delta and theta than $\mathrm{HC}$

Alpha activity was strongly decreased in both MCS and VS/ UWS as compared to HC

Positive correlation between CRS-R score and the power ratio of above $8 \mathrm{~Hz}$ to below $8 \mathrm{~Hz}$

Increased normalized delta power separated VS/UWS from MCS and from CS patients, whereas the converse occurred in higher frequency bands, with decreased normalized alpha power segregating VS/UWS from MCS and from CS patients

HC 26

MCS 19

VS/UWS 13

MCS 57

VS/UWS 85

MCS 6

VS/UWS 6 $80 \%$ of overall spectral power in VS/ UWS was concentrated within the delta band

VS/UWS had a significantly higher relative delta power in frontocentral and parieto-occipital than MCS

Significant correlations between CRS scores and relative delta power and relative alpha power in the fronto-central, parieto-occipital, and midline regions

MCS patients had higher theta and alpha and lower delta power than VS/UWS 
Table 1 (continued)

\begin{tabular}{|c|c|c|c|c|}
\hline Clinical application & Literature & Frequency bands & Subjects (numbers) & Main findings \\
\hline & Naro et al. [18] & $\begin{array}{l}\text { Delta, theta, alpha, beta, and } \\
\text { gamma }\end{array}$ & $\begin{array}{l}\text { HC } 10 \\
\text { MCS } 7 \\
\text { VS/UWS } 6\end{array}$ & $\begin{array}{l}\text { Alpha significantly correlated with } \\
\text { the consciousness level } \\
\text { MCS showed higher alpha, gamma } \\
\text { and theta, as well as lower delta } \\
\text { than VS/UWS }\end{array}$ \\
\hline & Naro et al. [25] & Theta and gamma & $\begin{array}{l}\text { HC } 10 \\
\text { MCS } 10 \\
\text { VS/UWS } 10\end{array}$ & $\begin{array}{l}\text { DOC patients showed higher theta } \\
\text { and lower gamma power than HC }\end{array}$ \\
\hline & Stefan et al. [19] & Delta and alpha & $\begin{array}{l}\text { MCS } 11 \\
\text { VS/UWS } 51\end{array}$ & $\begin{array}{l}\text { Alpha power was greater for MCS } \\
\text { patients than VS/UWS patients, } \\
\text { and conversely for delta power }\end{array}$ \\
\hline & Naro et al. [15] & Delta and alpha & $\begin{array}{l}\text { MCS } 15 \\
\text { VS/UWS } 17\end{array}$ & $\begin{array}{l}\text { Nearly } 80 \% \text { of the overall spectral } \\
\text { power was concentrated within } \\
\text { the delta band in patients with VS/ } \\
\text { UWS } \\
\text { MCS patients showed an alpha } \\
\text { power twice the patients with VS/ } \\
\text { UWS } \\
\text { Delta power decreased and the alpha } \\
\text { power increased with increase of } \\
\text { CRS-R score }\end{array}$ \\
\hline
\end{tabular}

\begin{tabular}{|c|c|c|c|c|c|}
\hline Clinical application & Literature & Frequency bands $\mathrm{F}$ & Follow-up time & nes Subjects (numbers) & Main findings \\
\hline \multirow[t]{3}{*}{ Prognosis } & Babiloni et al. [22] & Alpha & 3 months & $\begin{array}{l}\text { HC } 30 \\
\text { VS/UWS } 50\end{array}$ & $\begin{array}{l}\text { The higher of alpha power, the higher the } \\
\text { chance to recover consciousness }\end{array}$ \\
\hline & Sitt et al. [13] & Theta & $<42$ days & $\begin{array}{l}\text { HC } 14 \\
\text { CS } 24 \\
\text { MCS } 68 \\
\text { VS/UWS } 75\end{array}$ & $\begin{array}{l}\text { Patients recovering from VS/UWS tended to } \\
\text { exhibit a higher normalized theta power, } \\
\text { relative to non-recovering patients }\end{array}$ \\
\hline & Stefan et al. [19] & Delta and alpha & $589 \pm 1125$ day & $\begin{array}{ll}\text { yys } & \text { MCS } 11 \\
& \text { VS/UWS } 51\end{array}$ & $\begin{array}{l}\text { Alpha and delta performed better at } \\
\text { discriminating outcome than indexing } \\
\text { consciousness }\end{array}$ \\
\hline Clinical application & Literature & Frequency band & Treatment $\mathrm{S}$ & Subjects (numbers) & Main findings \\
\hline \multirow[t]{5}{*}{ Treatment } & Williams et al. [48] & $\sim 6-10 \mathrm{~Hz}$ activity & Zolpidem T & $\begin{array}{l}\text { Three diverse patients } \\
\text { with known zolpidem } \\
\text { responses }\end{array}$ & $\begin{array}{l}\text { Behavioral activation with zolpidem } \\
\text { reliably attenuated } \sim 6-10 \mathrm{~Hz} \text { power } \\
\text { and was associated with an increase in } \\
\text { power at } \sim 15-30 \mathrm{~Hz}\end{array}$ \\
\hline & Naro et al. [25] & Theta and gamma & otDCS & $\begin{array}{l}\text { HC } 10 \\
\text { MCS } 10 \\
\text { VS/UWS } 10\end{array}$ & $\begin{array}{l}\text { otDCS increased theta and gamma } \\
\text { power in healthy and MCS but not in } \\
\text { VS/UWS }\end{array}$ \\
\hline & Naro et al. [24] & Gamma & tACS & $\begin{array}{l}\text { HC } 15 \\
\text { MCS } 12 \\
\text { VS/UWS } 14\end{array}$ & $\begin{array}{l}\text { tACS entrained theta and gamma oscil- } \\
\text { lations and strengthened the connec- } \\
\text { tivity patterns within frontoparietal } \\
\text { networks in all HC and MCS, and } \\
\text { some VS/UWS }\end{array}$ \\
\hline & Bai et al. [26] & Delta and gamma & SCS & MCS 11 & $\begin{array}{l}\text { Relative power of delta significantly } \\
\text { decreased, while gamma increased } \\
\text { after one session of SCS }\end{array}$ \\
\hline & Hermann et al. [23] & Full band & tDCS & $\begin{array}{l}\text { EMCS } 4 \\
\text { MCS } 32 \\
\text { VS/UWS } 24\end{array}$ & $\begin{array}{l}\text { Responders showed a significant } \\
\text { increase in normalized theta power } \\
\text { with a maximal effect over the parietal } \\
\text { cortices and an increase of both raw } \\
\text { and normalized alpha power compared } \\
\text { to non-responders }\end{array}$ \\
\hline
\end{tabular}

$H C$ healthy control, DOC disorders of consciousness, EMCS emerged form minimally conscious state, $M C S$ minimally conscious state, $V S / U W S$ vegetative state/unresponsive wakefulness state, $L I S$ lock-in syndrome, CRS-R JFK Coma Recovery Scale-Revised, SND severe neurocognitive disorders, $C S$ conscious patients, $t D C S$ transcranial direct current stimulation, ot DCS oscillatory transcranial direct current stimulation, $t A C S$ transcranial alternating current stimulation, SCS spinal cord stimulation 
Table 2 Nonlinear EEG measurements in disorders of consciousness patients

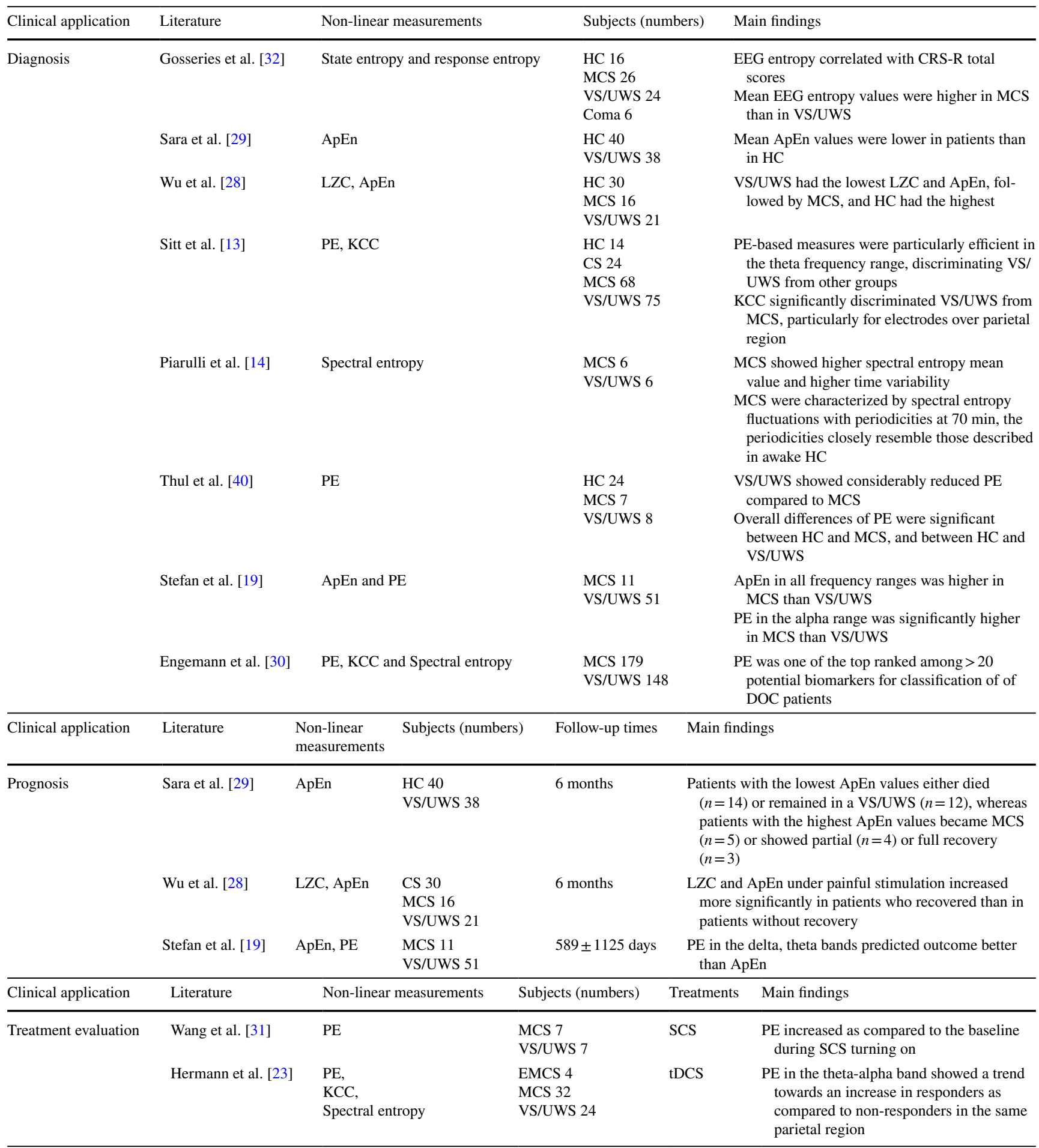

$H C$ healthy control, $D O C$ disorders of consciousness, $M C S$ minimally conscious state, $V S / U W S$ vegetative state/unresponsive wakefulness state, $C S$ conscious patients, $B I S$ bispectral index, $A p E n$ approximate entropy, LZC Lempel-Ziv Complexity, PE permutation entropy, KCC Kolmogorov-Chaitin complexity, $S C S$ spinal cord stimulation, $t D C S$ transcranial direct current stimulation

VS/UWS at 6-month follow-up, while patients with higher ApEn values are either in MCS, or partially or completely recovered [29].
Permutation entropy is effective in differentiating MCS from VS/UWS [13, 19]. A comparative study on EEG markers, including three non-linear indices, showed that only 


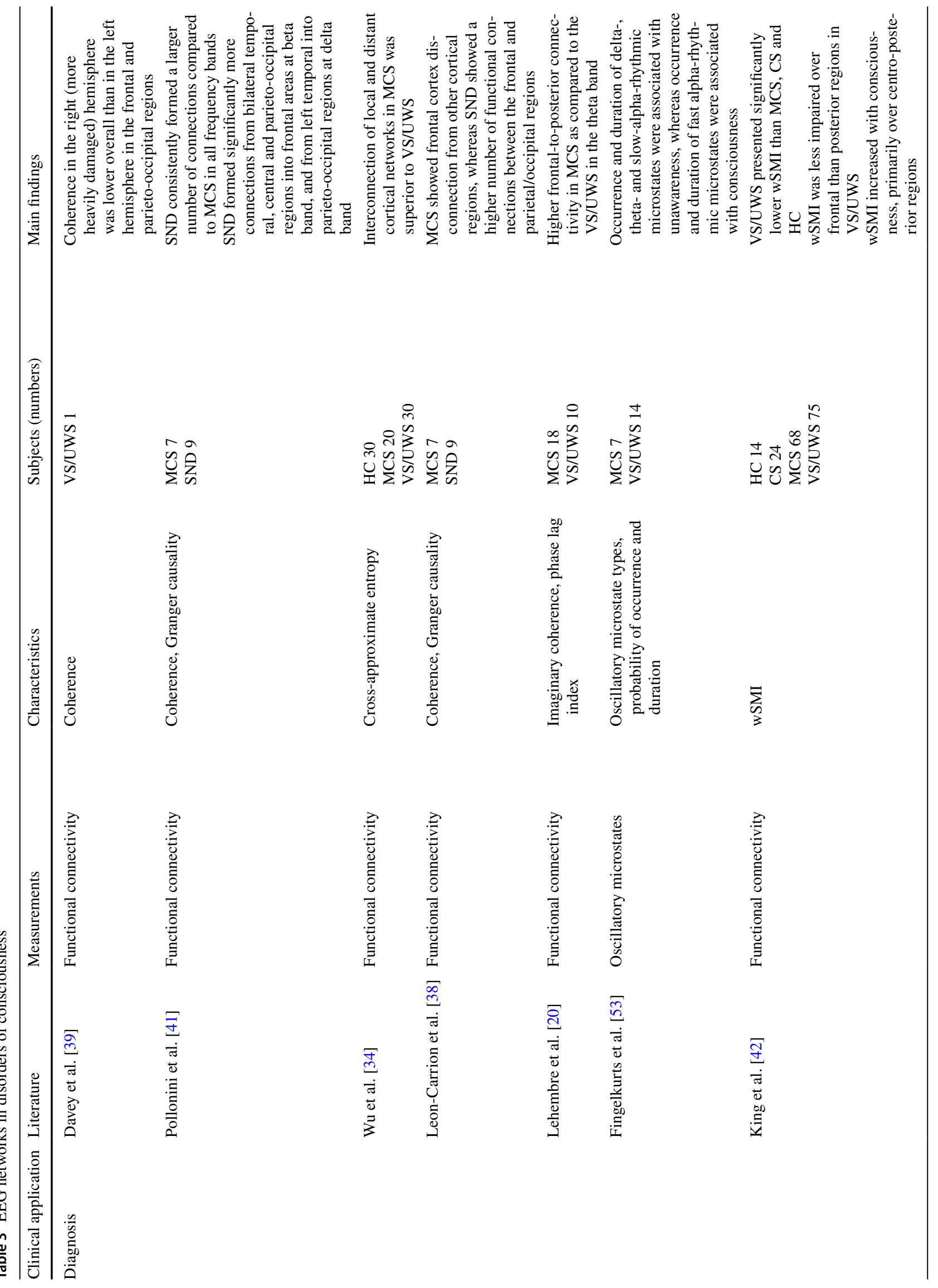




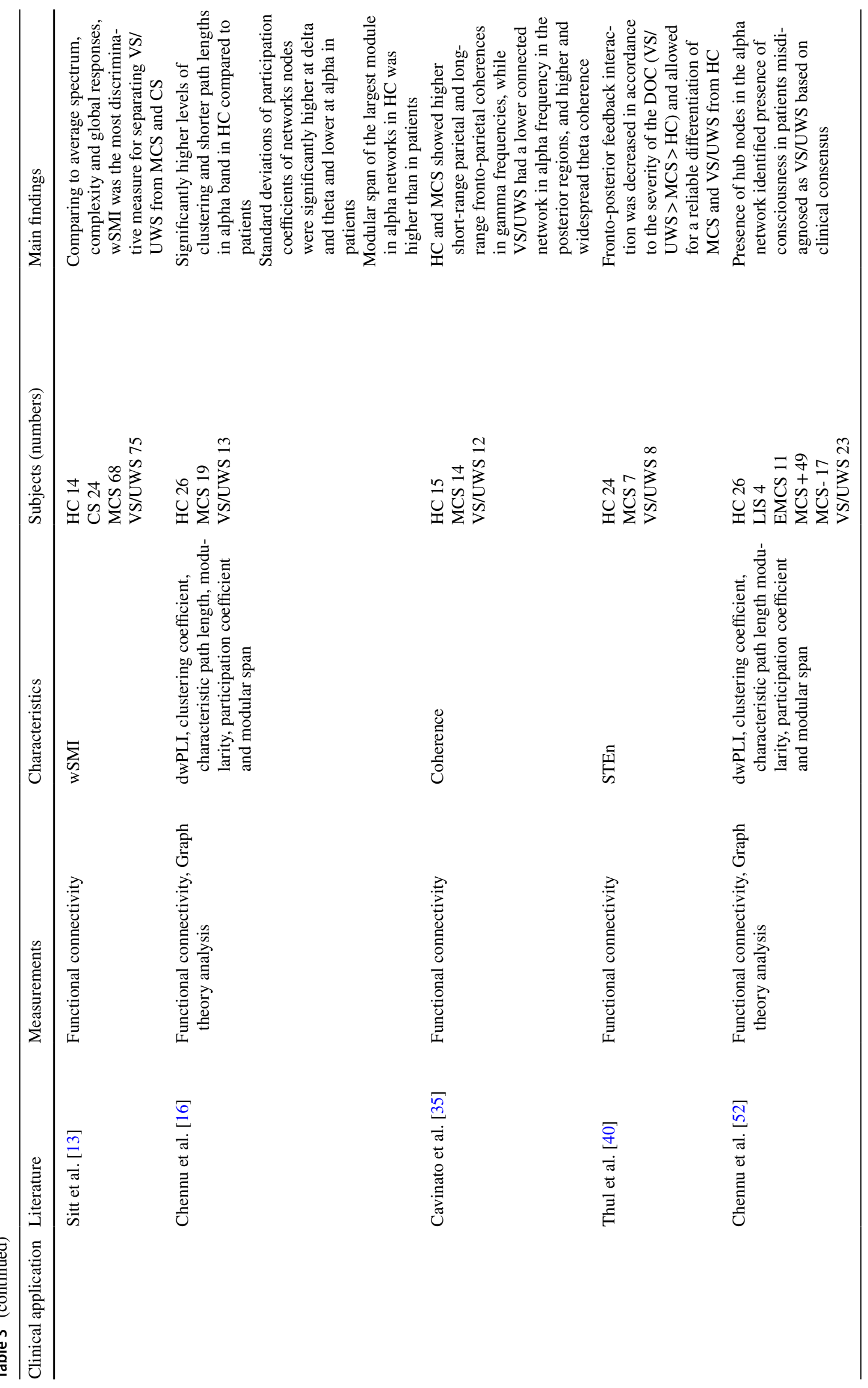




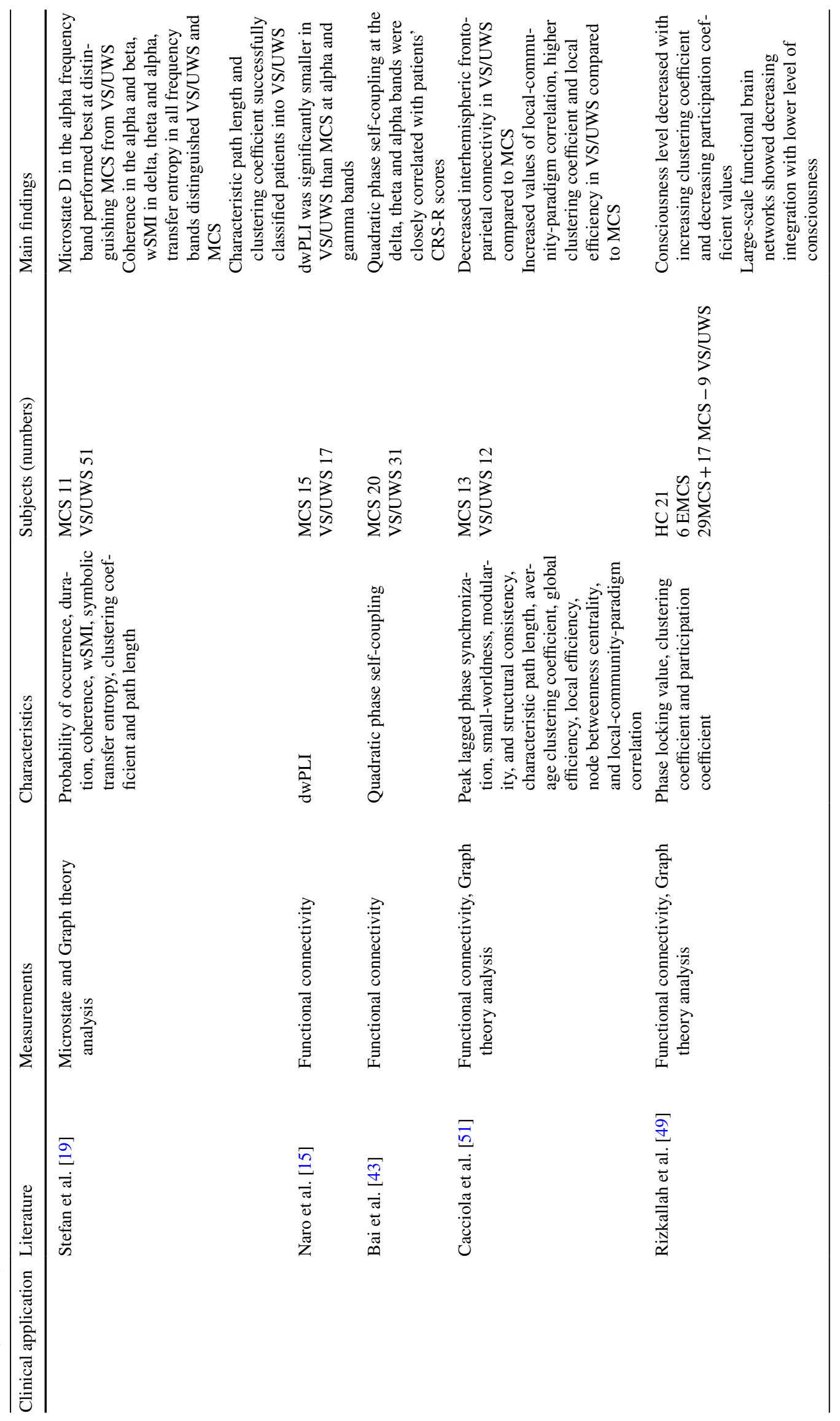




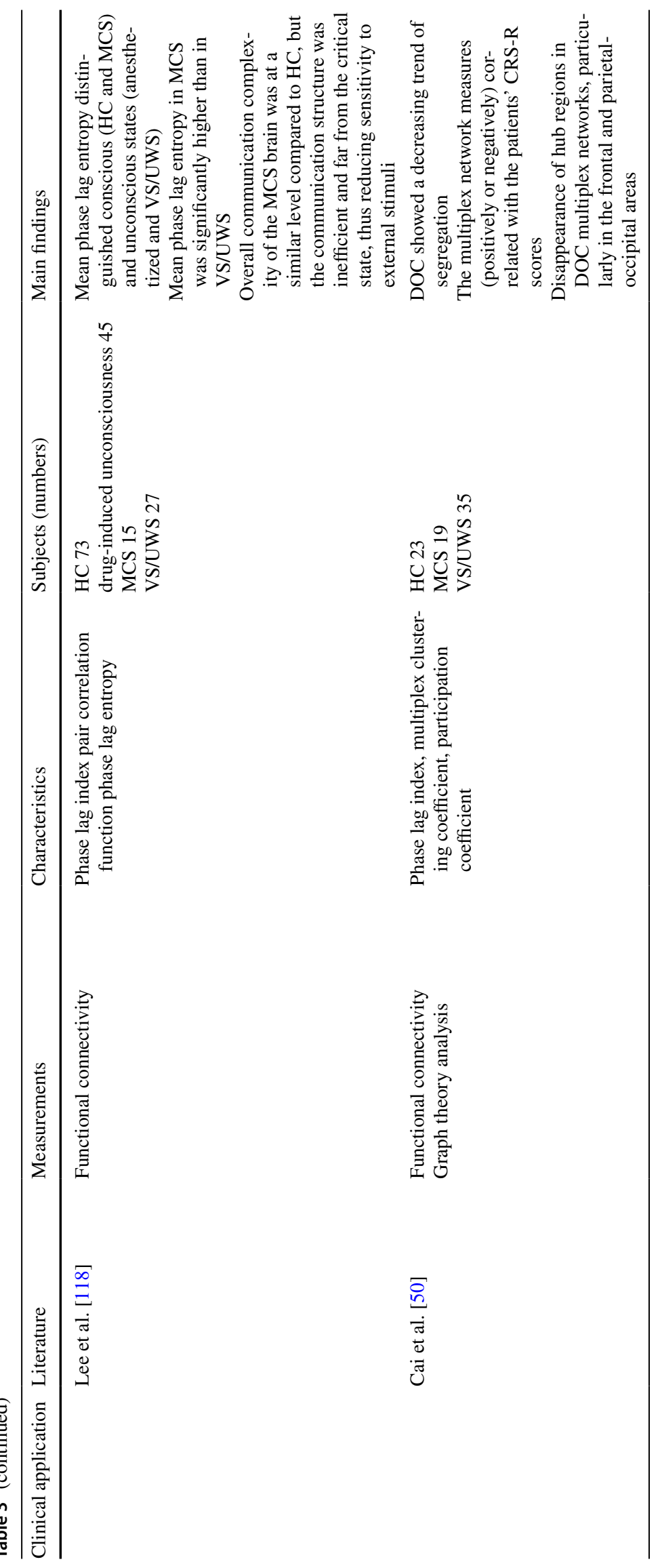




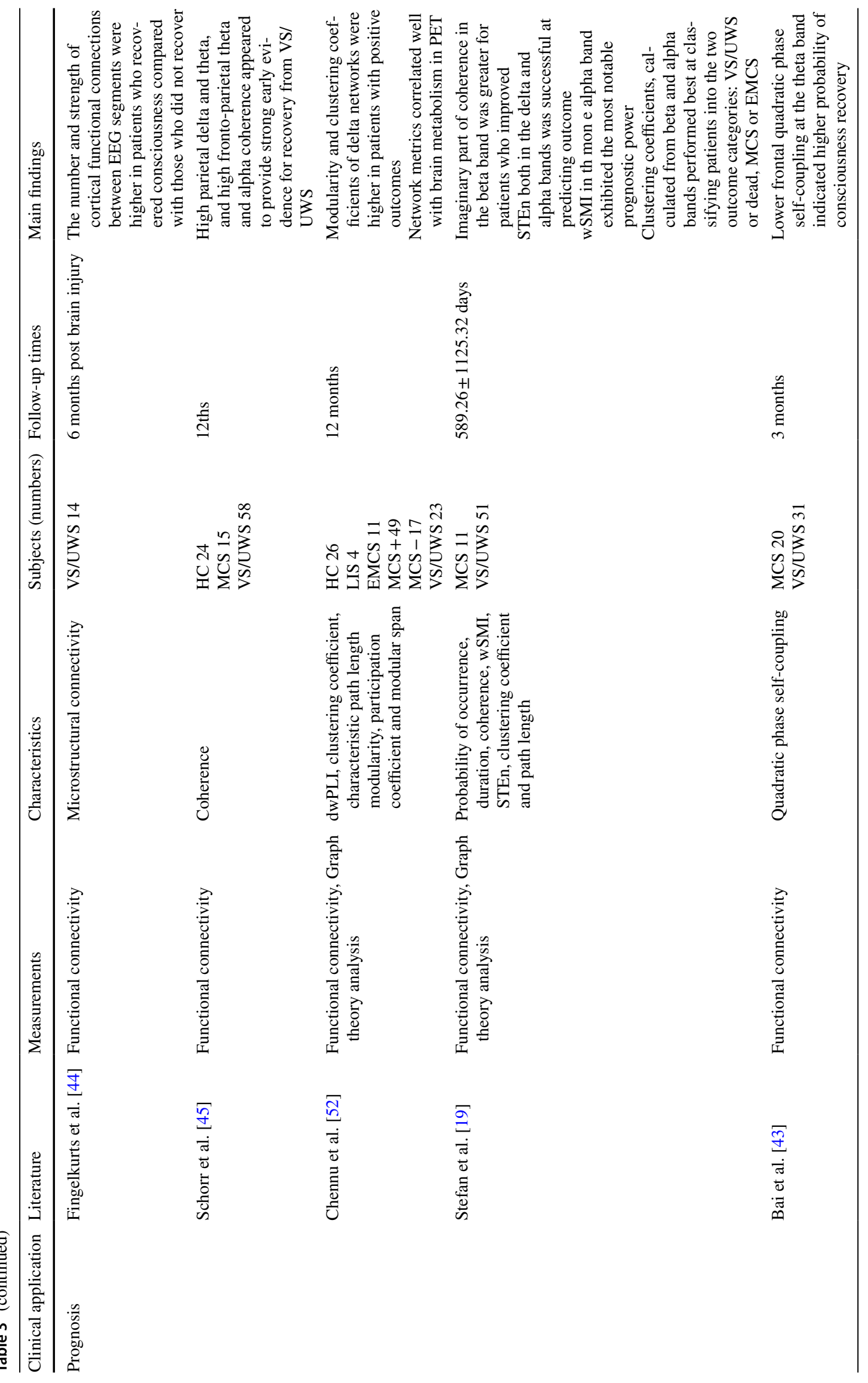




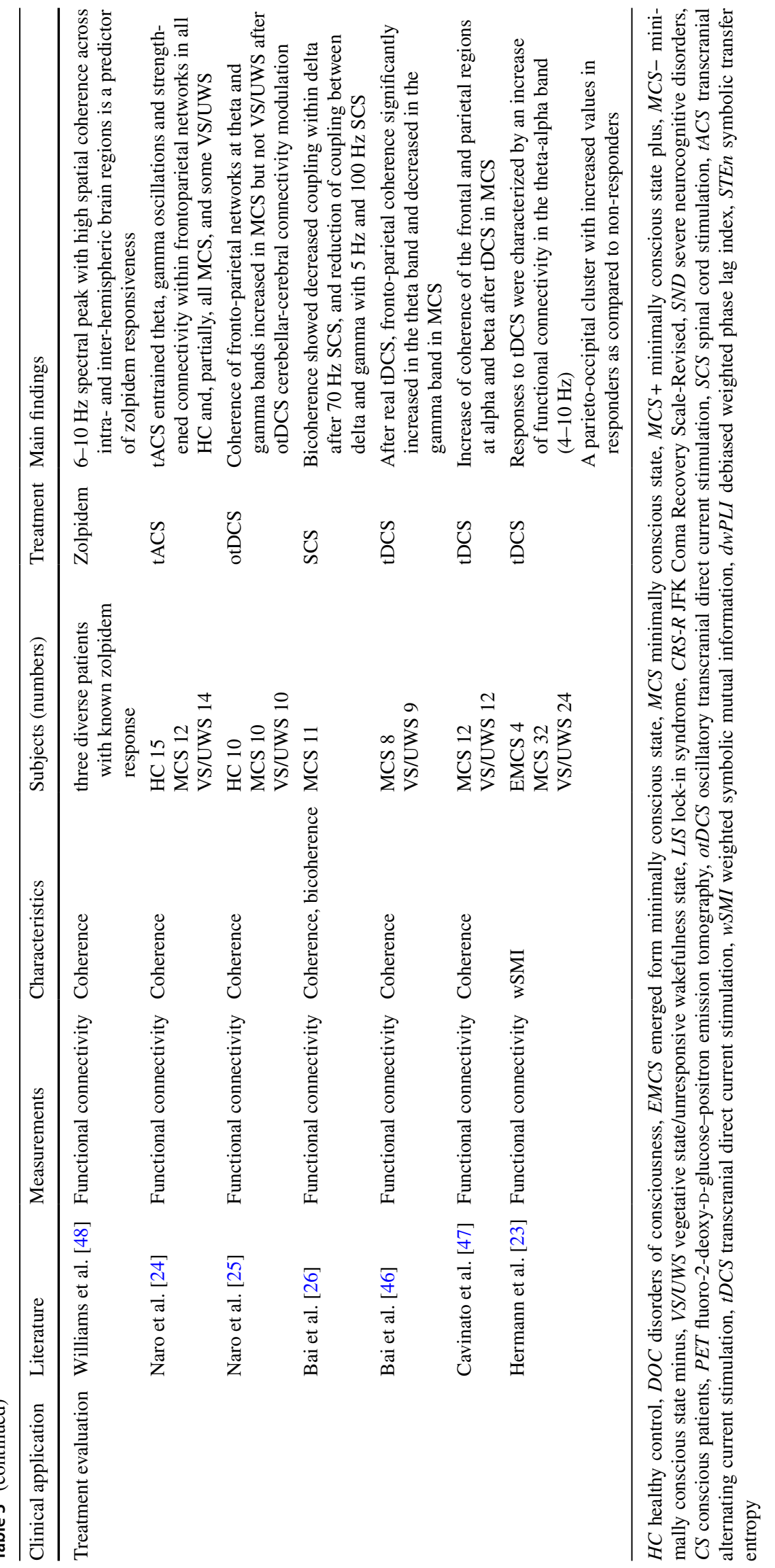


Table 4 EEG sleep patterns in disorders of consciousness

\begin{tabular}{|c|c|c|c|}
\hline Clinical application & Literature & Subjects (numbers) & Main findings \\
\hline \multirow[t]{12}{*}{ Diagnosis } & Oksenberg et al. [58] & VS/UWS 10 & $\begin{array}{l}\text { VS/UWS patients had a significant reduction in the phasic activities of } \\
\text { rapid eye movement sleep } \\
\text { The amount of sleep activities was unrelated to recovery from the clini- } \\
\text { cal condition }\end{array}$ \\
\hline & Isono et al. [59] & VS/UWS 12 & $\begin{array}{l}\text { In } 8 \text { VS/UWS patients, a clear sleep wake cycle was observed, and five } \\
\text { of them showed diffuse low voltage slow waves, with ripple-like activi- } \\
\text { ties shortly after the start of sleep }\end{array}$ \\
\hline & Landsness et al. [57] & $\begin{array}{l}\text { MCS } 6 \\
\text { VS/UWS } 5\end{array}$ & $\begin{array}{l}\text { Observed behavioral, but no electrophysiological, sleep wake patterns in } \\
\text { VS/UWS, while there were near-to-normal patterns of sleep in in MCS }\end{array}$ \\
\hline & Cologan et al. [61] & $\begin{array}{l}\text { MCS } 10 \\
\text { VS/UWS } 10\end{array}$ & $\begin{array}{l}\text { VS/UWS preserved sleep spindles, slow-wave sleep, and rapid eye move- } \\
\text { ment sleep }\end{array}$ \\
\hline & Malinowska et al. [64] & $\begin{array}{l}\text { LIS } 1 \\
\text { MCS } 20 \\
\text { VS/UWS } 11\end{array}$ & $\begin{array}{l}\text { MCS and LIS had significantly more sleep spindles, delta waves and } \\
\text { cycles of light and deep sleep than VS/UWS } \\
\text { Traumatic patients were more likely to show preserved EEG sleep-like } \\
\text { activities }\end{array}$ \\
\hline & Forgacs et al. [60] & $\begin{array}{l}\text { EMCS } 13 \\
\text { MCS } 23 \\
\text { VS/UWS } 8\end{array}$ & $\begin{array}{l}\text { Patients presenting vertex waves and sleep spindles had significantly } \\
\text { higher best CRS-R scores than the others }\end{array}$ \\
\hline & Mouthon et al. [56] & $\begin{array}{l}\text { CS } 5 \\
\text { EMCS } 1 \\
\text { MCS } 4\end{array}$ & $\begin{array}{l}\text { Children with DOC showed a global reduction in sleep-wave activities } \\
\text { regulation over parietal brain areas }\end{array}$ \\
\hline & Wislowska et al. [55] & $\begin{array}{l}\text { HC } 26 \\
\text { MCS } 17 \\
\text { VS/UWS } 18\end{array}$ & $\begin{array}{l}\text { Prevalence of sleep spindles and slow waves did not systematically vary } \\
\text { between day and night in patients } \\
\text { Day-night changes in EEG power spectra and signal complexity were } \\
\text { revealed in MCS but not VS/UWS } \\
\text { The more parietal spindles during night-time, the higher CRS-R scores }\end{array}$ \\
\hline & Pavlov et al. [62] & VS/UWS 15 & $\begin{array}{l}\text { Sleep stage N1 was observed in } 13 \text { patients, N2 in } 14 \text { patients, N3 in } 9 \\
\text { patients and REM sleep in } 10 \text { patients. Sleep spindles were found in } \\
\text { five patients } \\
\text { Stage N2 was mostly characterized by typical K-complexes, but spindles } \\
\text { were observed only in five patients, and their density was low }\end{array}$ \\
\hline & Rossi Sebastiano et al. [63] & $\begin{array}{l}\text { MCS } 36 \\
\text { VS/UWS } 49\end{array}$ & $\begin{array}{l}\text { The presence of slow-wave sleep was the most appropriate factor for } \\
\text { classifying patients as VS/UWS or MCS } \\
\text { Duration of slow-wave sleep was demonstrated as the main factor that } \\
\text { significantly correlated with patients' CRS-R scores }\end{array}$ \\
\hline & Wielek et al. [66] & $\begin{array}{l}\text { MCS } 11 \\
\text { VS/UWS } 12\end{array}$ & $\begin{array}{l}\text { MCS were more likely to wake up during the day and had more complex } \\
\text { patterns of sleep-wake stages at night, while VS/UWS did not show } \\
\text { any accumulation of specific conditions during the day or night }\end{array}$ \\
\hline & Zieleniewska et al. [65] & $\begin{array}{l}\text { EMCS } 5 \\
\text { MCS } 6 \\
\text { VS/UWS } 8\end{array}$ & $\begin{array}{l}\text { Power and detrended fluctuation analysis of sleep spindles, detrended } \\
\text { fluctuation analysis of slow waves and times of deep sleep were higher } \\
\text { in the MCS/EMCS groups than VS/UWS }\end{array}$ \\
\hline Clinical application & Literature & \multicolumn{2}{|c|}{ Follow-up times Main findings } \\
\hline
\end{tabular}

$H C$ healthy control, DOC disorders of consciousness, EMCS emerged form minimally conscious state, MCS minimally conscious state, VS/UWS vegetative state/unresponsive wakefulness state, $L I S$ lock-in syndrome, $C R S-R$ FK Coma Recovery Scale-Revised, $C S$ conscious patients

permutation entropy and Kolmogorov-Chaitin complexity significantly differentiate between VS/UWS and MCS [13]. Consistently, permutation entropy is as one of the top ranking among over 20 potential biomarkers in the classification of different consciousness states of DOC patients [30]. Permutation entropy is also a sensitive index responding to brain stimulation treatment [31]. Moreover, permutation entropy in the delta and theta bands shows better performance than ApEn as a prognostic index in predicting outcome of DOC patients [19] (Table 2).

Non-linearity in the frequency domain Spectral entropy is a non-linear quantitative parameter of specific spectral EEG powers. VS/UWS patients have lower spectral entropy values than MCS patients and fully conscious patients [13]. MCS exhibits periodic (over $70 \mathrm{~min}$ ) fluctuations of spectral 


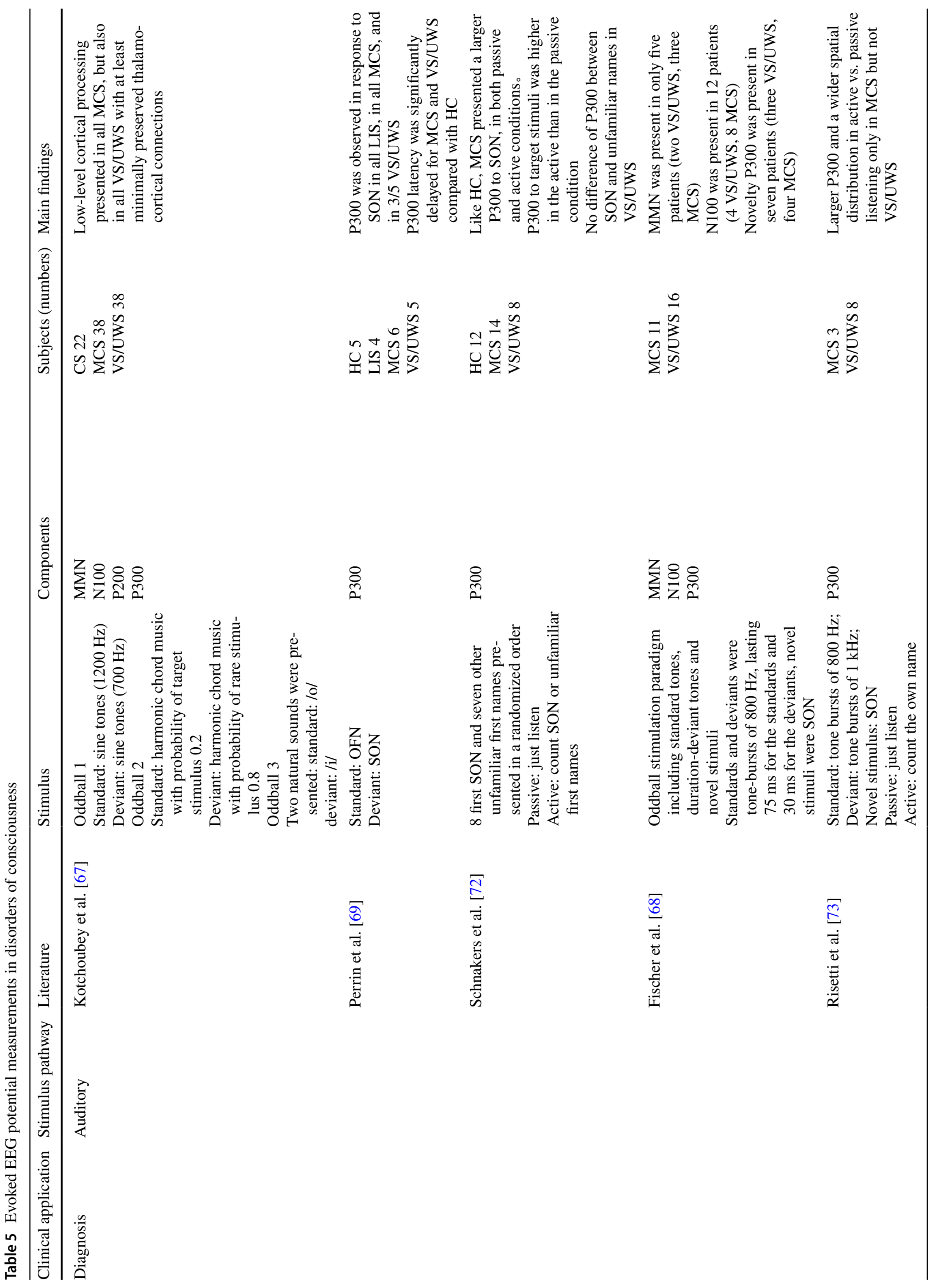




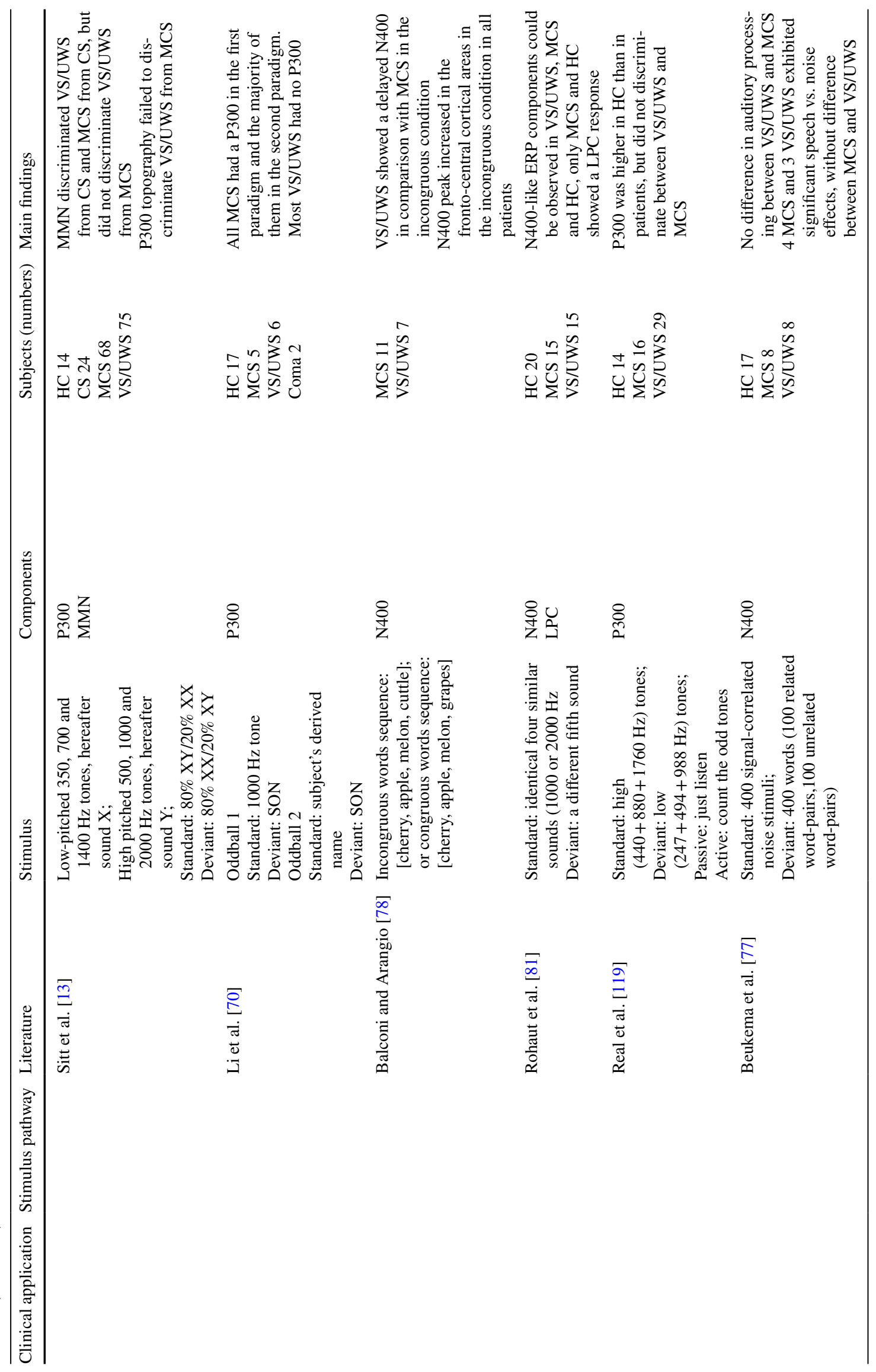




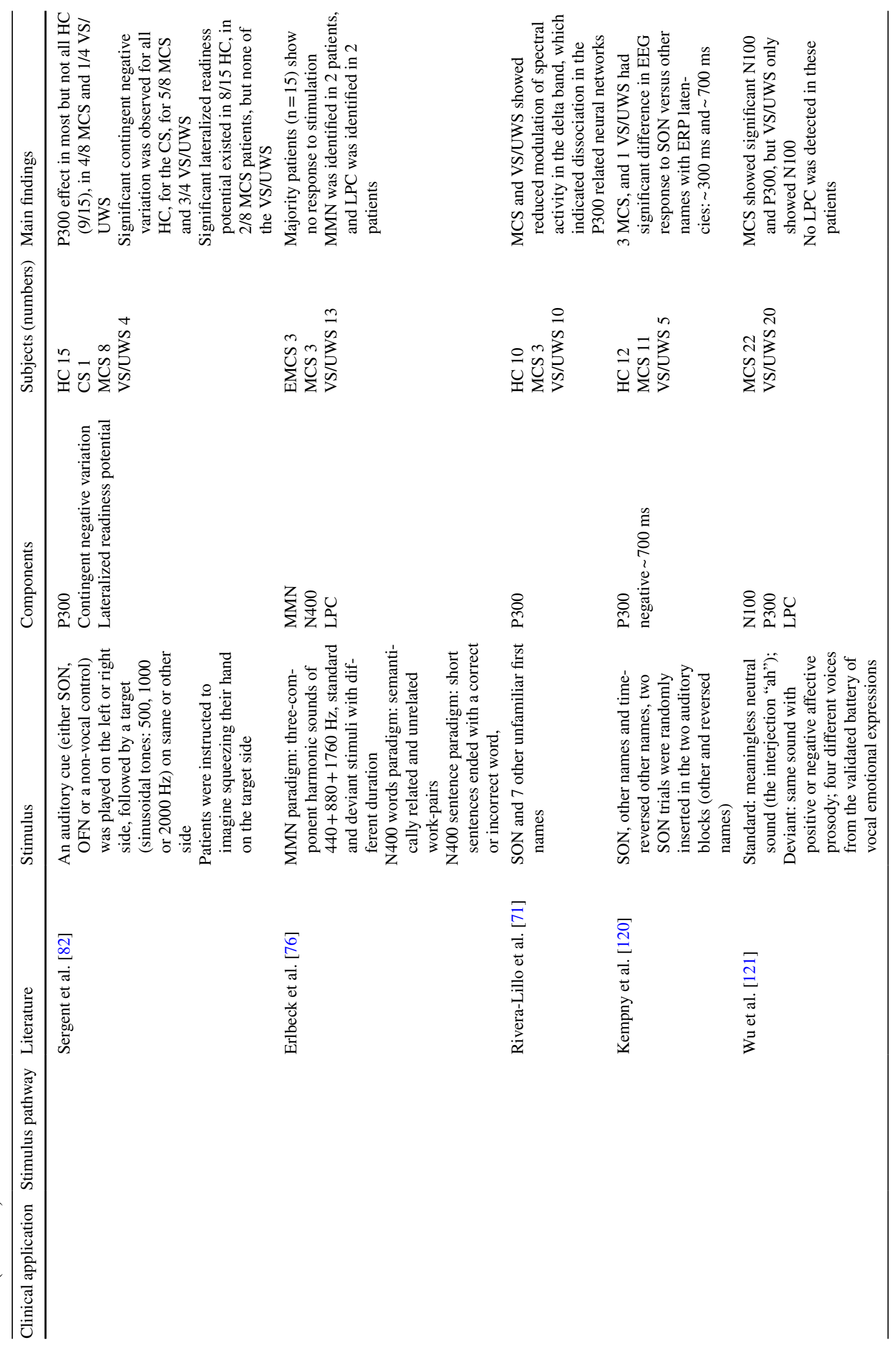




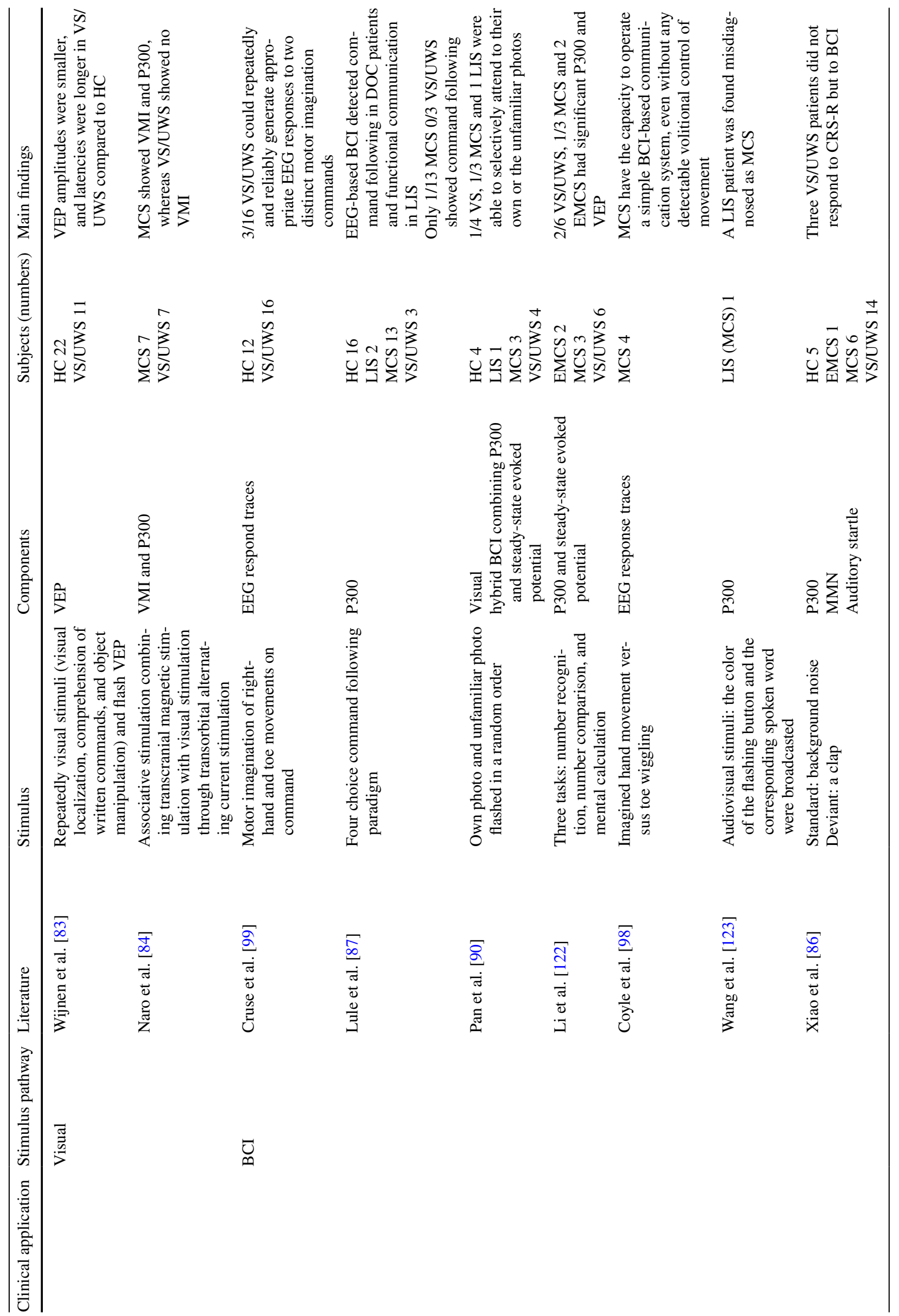




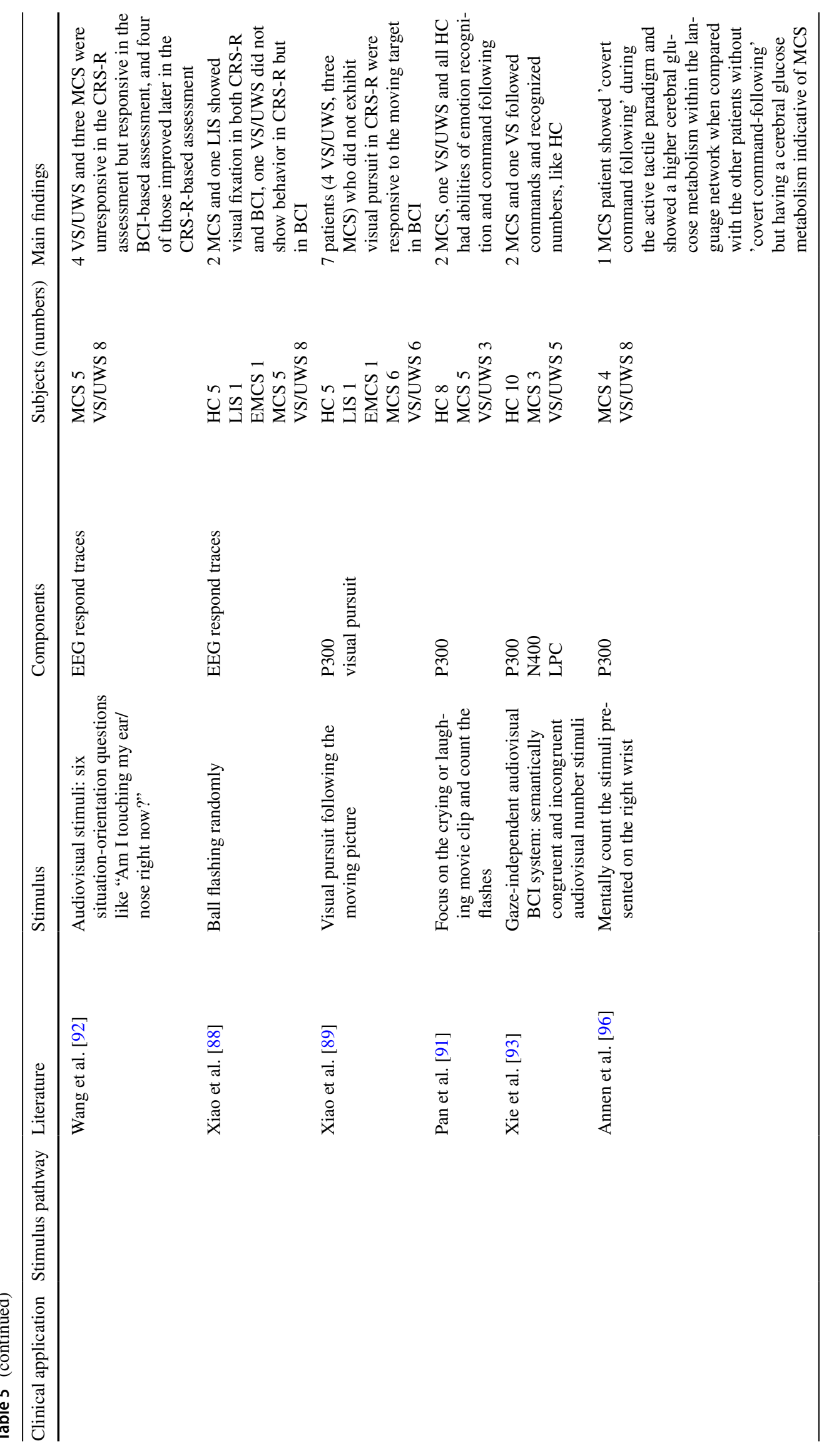




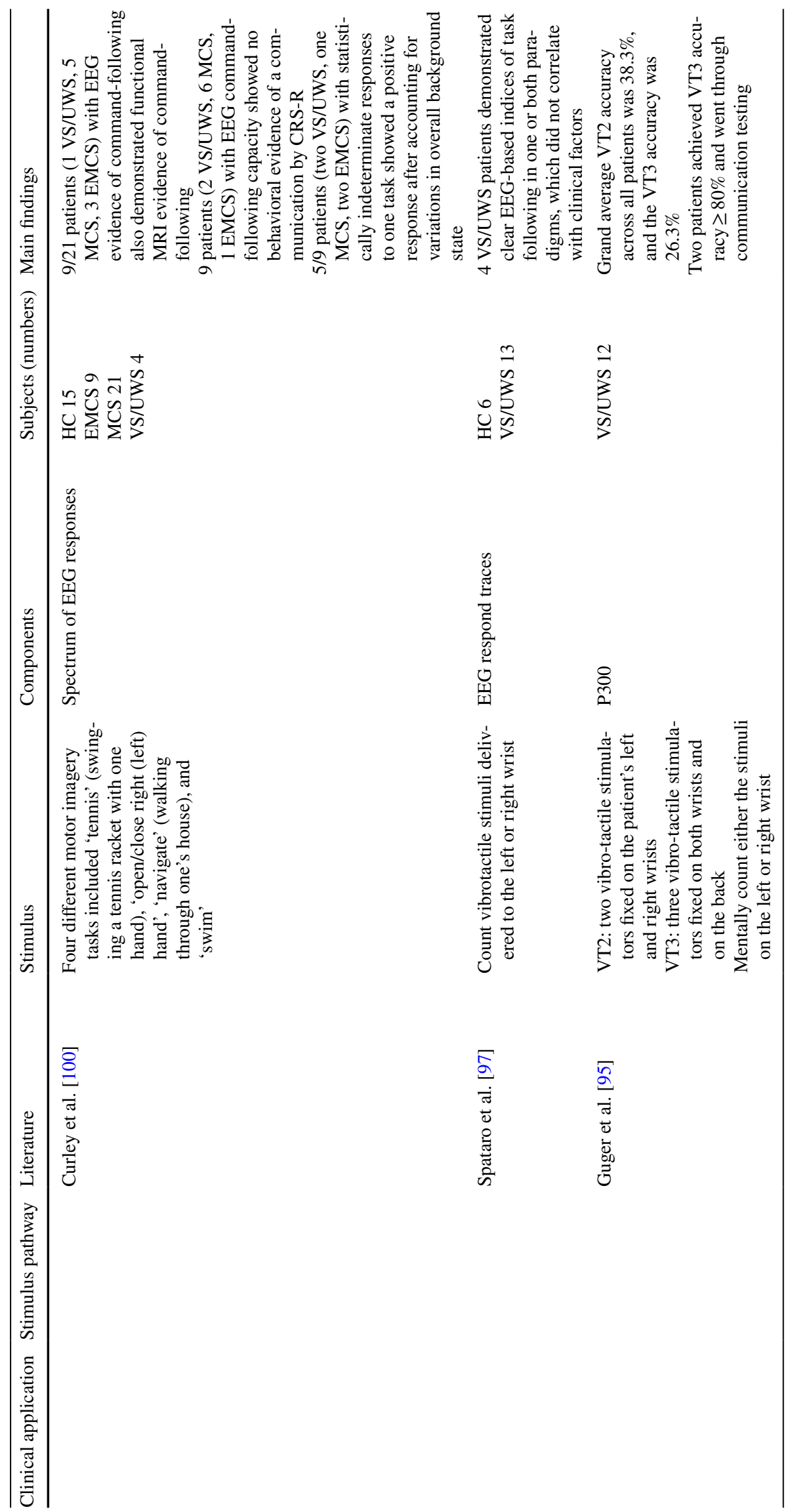




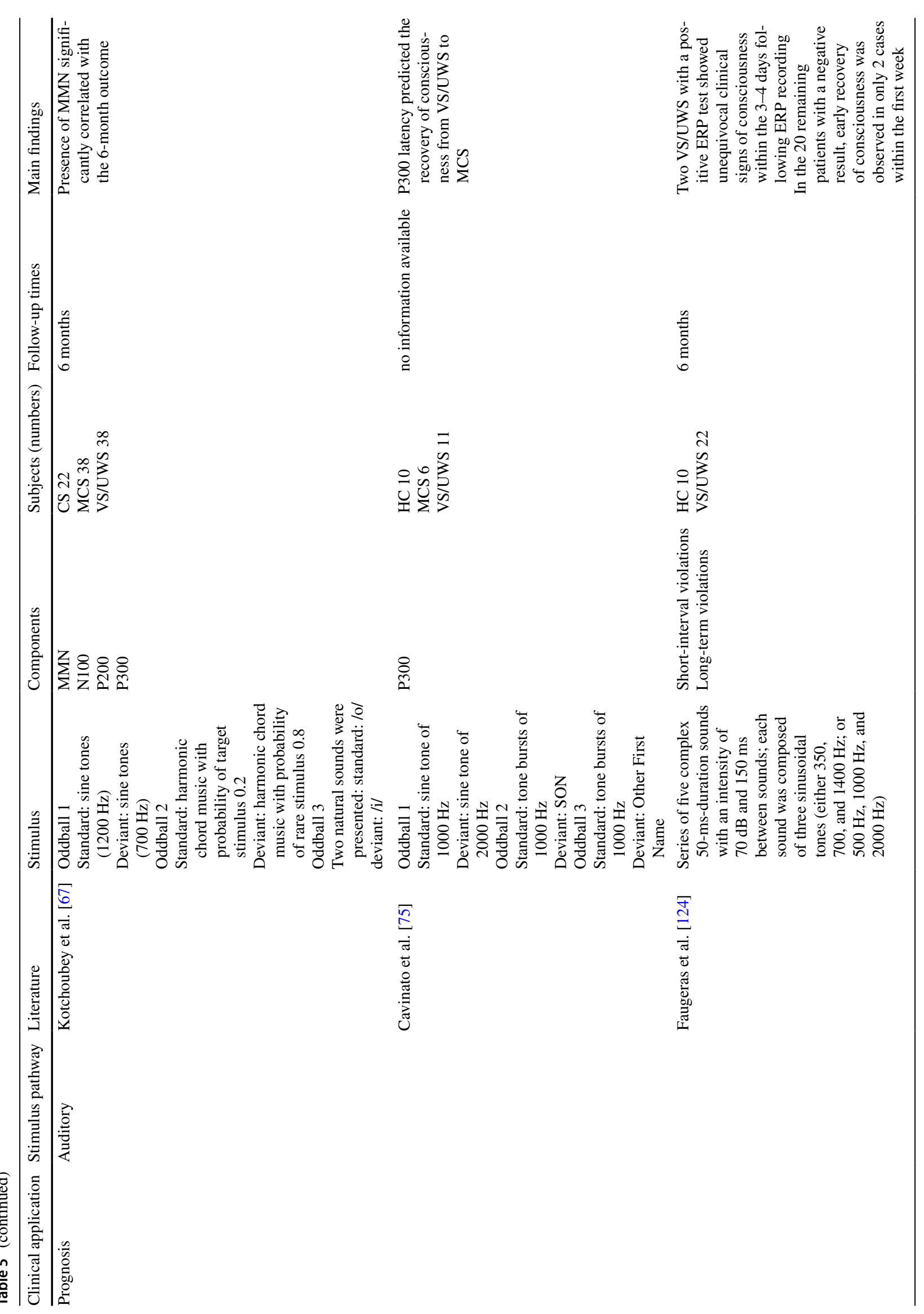




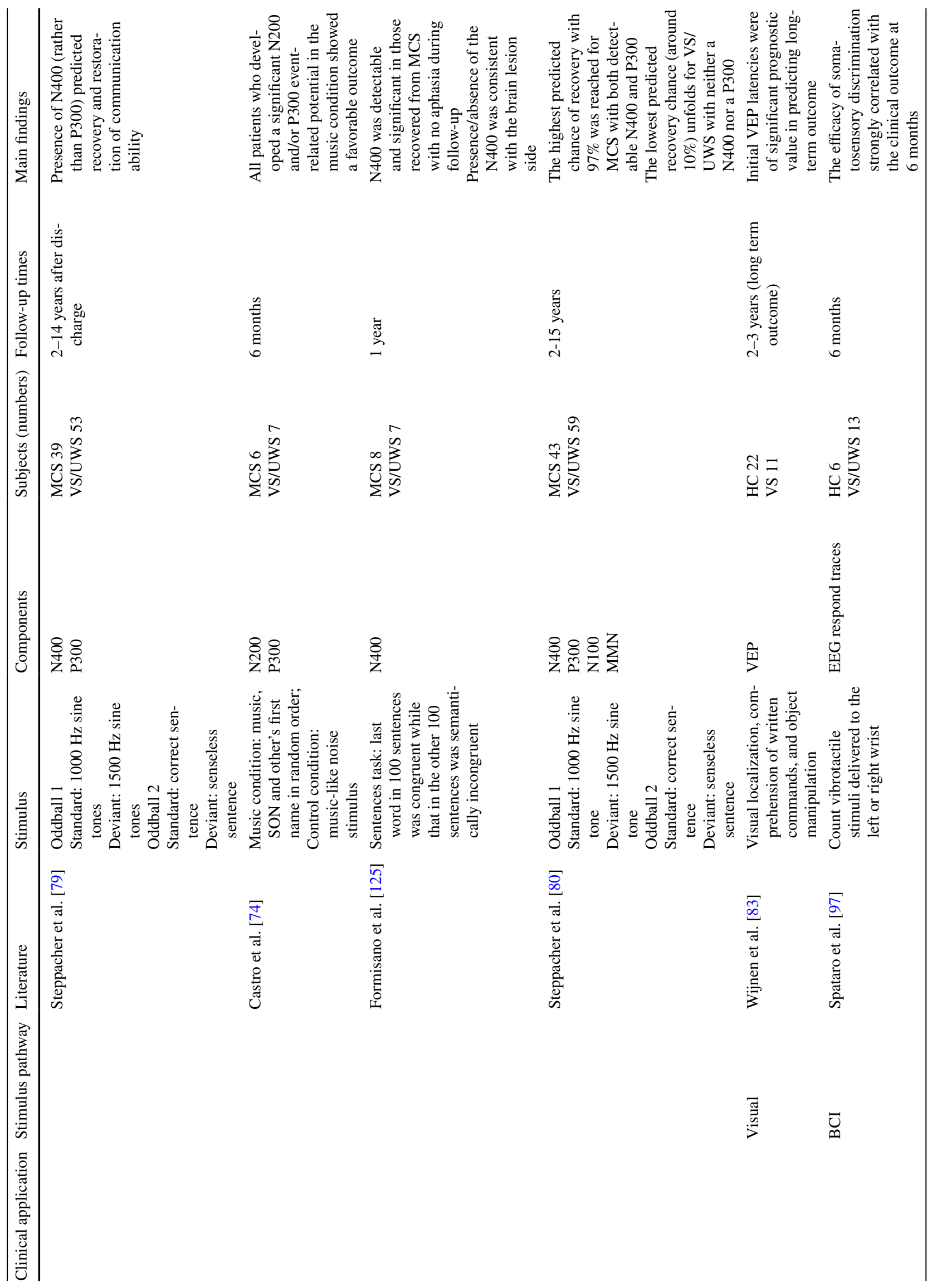




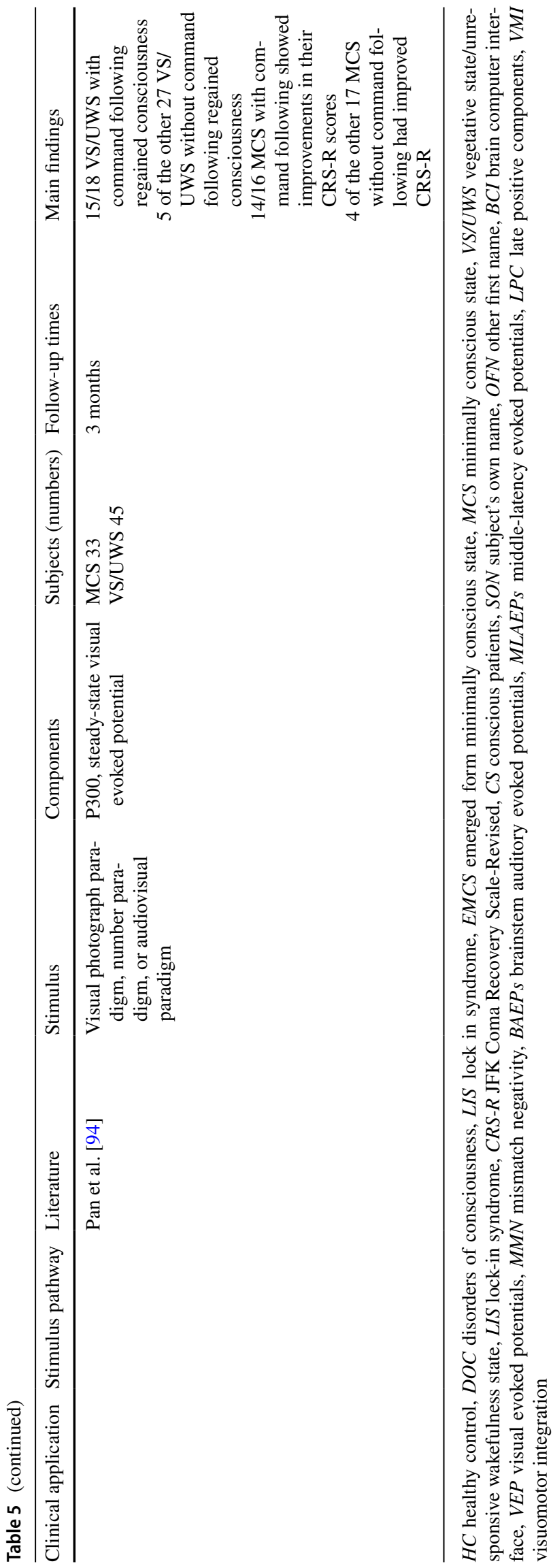

entropy similar to HC. In contrast, VS/UWS does not show any distinct periodic fluctuations [14]. State entropy, reaction entropy and bispectral index (BIS), which were used in detecting the depth of anesthesia, are also effective in distinguishing VS/UWS from MCS with sensitivity of $89 \%$ and specificity of $90 \%$ [32] (Table 2). The state entropy values of VS/UWS and MCS are 49\% and 18\% lower, respectively, than of HC. Consistently, lower consciousness levels correspond to lower BIS in DOC patients [33]. Moreover, BIS correlates positively with the CRS-R, and the 1-year outcome of DOC patients [33].

\section{Brain networks}

Functional connectivity DOC patients with a better state of consciousness tend to show stronger functional connectivity among brain regions $[34,35]$ (Table 3 ). The prefrontal cortex plays a crucial role in the formation of consciousness $[36,37]$. Disconnection between the frontal and parietal and occipital regions discriminates between MCS patients and individuals with severe neurocognitive disorders [38]. MCS has a higher phase lag index and imaginary coherence between the frontal and posterior regions than VS/UWS [20]. Coherence between the frontal and occipital regions in the ipsilesional hemisphere is lower than in the contralesional hemisphere in VS/UWS [39]. Symbolic transfer entropy analysis also shows that the feedback interaction between the frontal-parietal and frontal-temporal regions is particularly affected in DOC patients [40]. MCS patients show less connectivity between temporal and parietaloccipital regions than patients with severe neurocognitive disorders [41].

Furthermore, MCS and VS/UWS show significantly abnormal connectivity dynamics, especially in the frontotemporal, frontocentral and centro-parietooccipital regions [15]. Connectivity measured by weighted symbolic mutual information increases over central-posterior regions with increasing levels of consciousness [42].

Connectivity measured in theta, alpha and gamma bands shows significance in distinguishing consciousness levels. Compared with VS/UWS, MCS has a higher phase lag index in the alpha band [20], an increasing debiased estimator of the squared weighted phase lag index in the gamma band, and a lower coherence in the theta band [15, 35]. In addition to traditional connectivity measurements, bicoherence measures the quadratic phase coupling characteristics of the EEG oscillations within the same sources. Quadratic phase self-coupling in the delta, theta and alpha bands is closely correlated with the CRS-R score [43].

Functional connectivity measurement also showed utility in the outcome prediction of DOC patients. In a 3-month prognostic study, the number and intensity of cortical 
Table 6 TMS-EEG measurements in disorders of consciousness

\begin{tabular}{|c|c|c|c|c|c|c|}
\hline Clinical application & \multicolumn{2}{|l|}{ Literature } & \multicolumn{2}{|c|}{ Characteristics } & Subjects (numbers) & Main findings \\
\hline \multirow[t]{8}{*}{ Diagnosis } & \multicolumn{2}{|c|}{ Rosanova et al. [104] } & \multicolumn{2}{|l|}{$\begin{array}{l}\text { TEP } \\
\text { GMFP }\end{array}$} & $\begin{array}{l}\text { LIS } 2 \\
\text { MCS } 5 \\
\text { VS/UWS } 5\end{array}$ & $\begin{array}{l}\text { In VS/UWS, TMS triggered a simple, local response } \\
\text { In MCS, TMS invariably triggered complex responses that } \\
\text { sequentially involved distant cortical areas ipsi- and con- } \\
\text { tralateral to the site of stimulation, similar to responses in } \\
\text { LIS }\end{array}$ \\
\hline & \multicolumn{2}{|l|}{ Casali et al. [110] } & \multicolumn{2}{|l|}{ PCI } & $\begin{array}{l}\text { LIS } 2 \\
\text { EMCS } 6 \\
\text { MCS } 6 \\
\text { VS/UWS } 6\end{array}$ & $\begin{array}{l}\text { PCI range: } \\
\text { VS/UWS } 0.19-0.31 \\
\text { LIS } 0.51-0.62 \\
\text { MCS } 0.32-0.49 \\
\text { EMCS } 0.37-0.52 \\
\text { Wake } 0.44-0.67\end{array}$ \\
\hline & \multicolumn{2}{|c|}{ Ragazzoni et al. [107] } & \multicolumn{2}{|l|}{ TEP } & $\begin{array}{l}\text { HC } 5 \\
\text { MCS } 5 \\
\text { VS/UWS } 8\end{array}$ & $\begin{array}{l}\text { TEP results suggest that cortical reactivity and connectivity } \\
\text { are severely impaired in all VS/UWS, whereas in most MCS, } \\
\text { TEP are preserved but with abnormal features }\end{array}$ \\
\hline & \multicolumn{2}{|c|}{ Gosseries et al. [126] } & \multicolumn{2}{|l|}{ TEP } & $\begin{array}{l}\text { HC } 8 \\
\text { VS/UWS } 3\end{array}$ & $\begin{array}{l}\text { TEP are genuine cortical responses detectable only when } \\
\text { preserved cortical tissue is stimulated }\end{array}$ \\
\hline & \multicolumn{2}{|c|}{ Formaggio et al. [127] } & \multicolumn{2}{|c|}{$\begin{array}{l}\text { TEP with time- } \\
\text { frequency } \\
\text { analysis }\end{array}$} & $\begin{array}{l}\text { HC } 5 \\
\text { MCS } 1 \\
\text { VS/UWS } 4\end{array}$ & $\begin{array}{l}\text { Early synchronization, particularly over motor areas for alpha } \\
\text { and beta and over the frontal and parietal electrodes for beta } \\
\text { power in DOC patients } \\
\text { No relevant modification in slow rhythms (delta and theta) } \\
\text { after TMS in DOC patients }\end{array}$ \\
\hline & \multicolumn{2}{|c|}{ Casarotto et al. [112] } & \multicolumn{2}{|l|}{$\begin{array}{l}\text { PCI } \\
\text { PCImax }\end{array}$} & $\begin{array}{l}\text { LIS } 5 \\
\text { EMCS } 9 \\
\text { MCS }+17 \\
\text { MCS }-21 \\
\text { VS/UWS } 43\end{array}$ & $\begin{array}{l}\text { PCImax was lower in MCS (range }=0.27-0.55 \text { ) as compared to } \\
\text { conscious brain-injured patients } \\
\text { PCImax had a sensitivity of } 94.7 \% \text { in detecting minimal signs } \\
\text { of consciousness } \\
\text { VS/UWS had } 3 \text { different subgroups: a "no response" subgroup } \\
\text { (PCImax }=0 \text { ) of } 13 \text { patients }(30 \%) \text {, a "low-complexity" } \\
\text { subgroup (PCImax }<0.31 \text { ) of } 21 \text { patients }(49 \%) \text {, and a "high- } \\
\text { complexity" subgroup (PCImax }>0.31 \text { ) of } 9 \text { patients }(21 \%)\end{array}$ \\
\hline & \multicolumn{2}{|l|}{ Bodart et al. [113] } & \multicolumn{2}{|l|}{$\begin{array}{l}\text { PCI } \\
\text { PCImax }\end{array}$} & $\begin{array}{l}\text { LIS } 2 \\
\text { EMCS } 2 \\
\text { MCS } 11 \\
\text { VS/UWS } 9\end{array}$ & $\begin{array}{l}\text { PCI was highly consistent with FDG-PET in classifying MCS } \\
\text { vs. VS/UWS } \\
\text { Four patients (VS/UWS, diagnosed by CRS-R) had high PCI } \\
\text { and preserved FDG-PET }\end{array}$ \\
\hline & \multicolumn{2}{|c|}{ Rosanova et al. [108] } & \multicolumn{2}{|l|}{$\begin{array}{l}\text { TEP } \\
\text { PCI }\end{array}$} & $\begin{array}{l}\mathrm{HC} 20 \\
\text { VS/UWS } 16\end{array}$ & $\begin{array}{l}\text { VS/UWS had cortical OFF-periods, similar to those in HC } \\
\text { during sleep }\end{array}$ \\
\hline Clinical application & \multicolumn{2}{|l|}{ Literature } & Charac & eristics & Subjects (numbers) & Main findings \\
\hline Prognosis & Casarotto et al. [1 & & $\begin{array}{l}\text { PCI } \\
\text { PCIma }\end{array}$ & & $\begin{array}{l}\text { LIS } 5 \\
\text { EMCS } 9 \\
\text { MCS }+17 \\
\text { MCS }-21 \\
\text { VS/UWS } 43\end{array}$ & $\begin{array}{l}\text { Concerning the outcome at } 6 \text { months, } 6 \text { of } 9(1 \\
\text { unknown) high-complexity (PCImax }>0.31) \text { VS/ } \\
\text { UWS transitioned to a behavioral MCS, whereas such } \\
\text { transition was observed in } 5 \text { of } 21(2 \text { unknown) low- } \\
\text { complexity VS/UWS (PCImax }<0.31)\end{array}$ \\
\hline & Bodart et al. [113 & & $\begin{array}{l}\text { PCI } \\
\text { PCIma }\end{array}$ & & $\begin{array}{l}\text { LIS } 2 \\
\text { EMCS } 2 \\
\text { MCS } 11 \\
\text { VS/UWS } 9\end{array}$ & $\begin{array}{l}1 \text { VS/UWS with relatively preserved whole right } \\
\text { hemisphere metabolism but } \mathrm{PCI}<0.31 \text { did not show } \\
\text { improvement and remained VS/UWS after a follow-up } \\
\text { of } 5 \text { years }\end{array}$ \\
\hline Clinical application & Literature & Cha & acteristics & Treatmen & nt Subjects (numbers) & Main findings \\
\hline Treatment evaluation & Bai et al. [109] & GM & & $\mathrm{tDCS}$ & $\begin{array}{l}\text { MCS } 7 \\
\text { VS/UWS } 9\end{array}$ & $\begin{array}{l}\text { tDCS induced global TEP responses in MCS but only } \\
\text { local responses in VS/UWS }\end{array}$ \\
\hline & Bai et al. [114] & $\begin{array}{l}\text { TEP } \\
\text { GM } \\
\text { PCI }\end{array}$ & & rTMS & $\begin{array}{l}\text { HC } 5 \\
\text { MCS } 1\end{array}$ & $\begin{array}{l}\text { Along with consciousness recovery in one MCS, TEP and } \\
\text { PCI tended to become gradually similar to those of HC }\end{array}$ \\
\hline
\end{tabular}

$H C$ healthy control, $D O C$ disorders of consciousness, EMCS emerged form minimally conscious state, $M C S$ minimally conscious state, VS/UWS vegetative state/unresponsive wakefulness state, LIS lock-in syndrome, CRS-R JFK Coma Recovery Scale-Revised, TEP TMS evoked Potential, GMFP global mean field power, PCI perturbational complexity index, PCImax max PCI, $t D C S$ transcranial direct current stimulation, TMS transcranial magnetic stimulation, $r T M S$ repetitive transcranial magnetic stimulation 


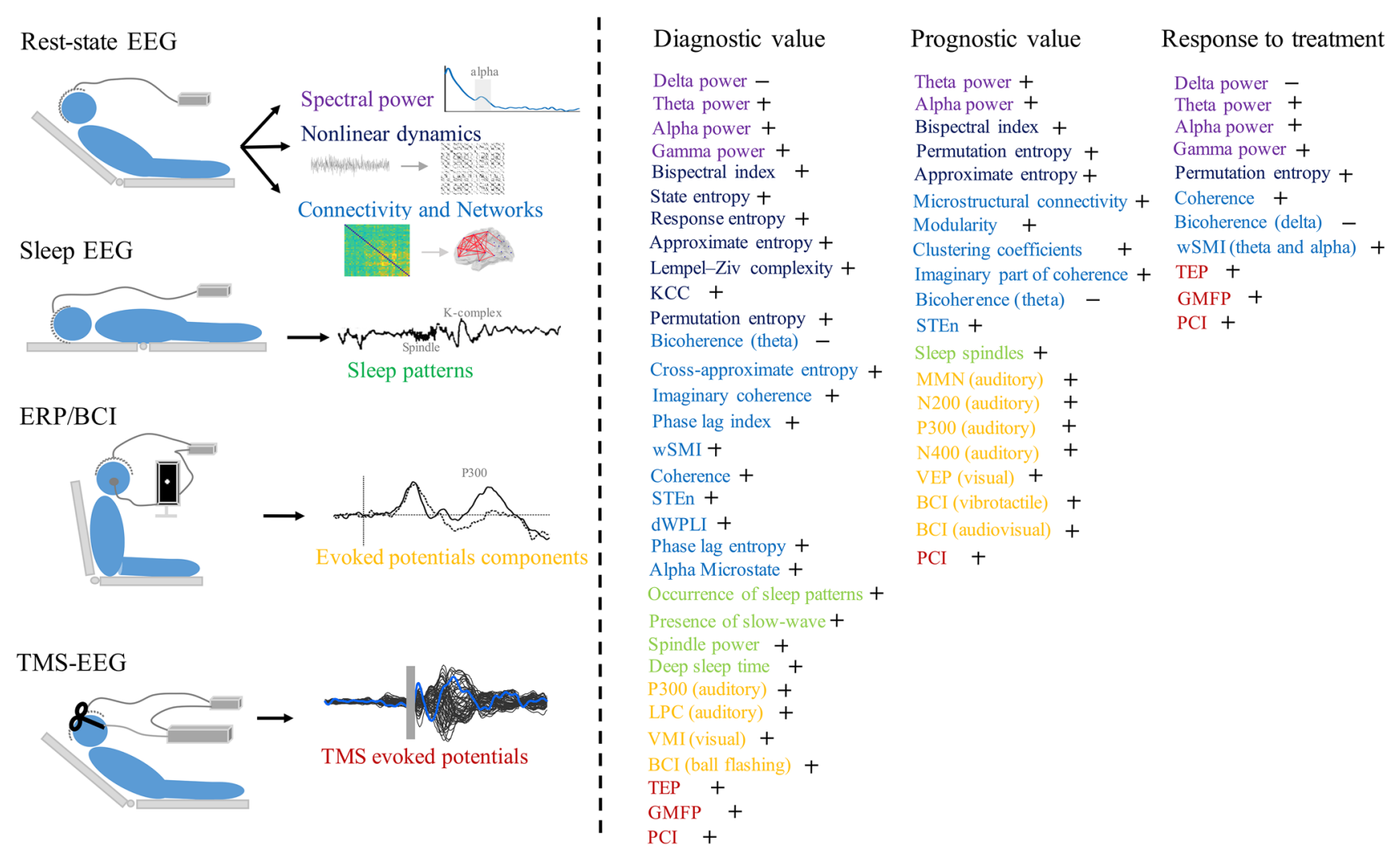

Fig. 1 Main EEG measures obtained in patients with disorders of consciousness: rest-state EEG, sleep EEG, event-related potentials (ERP), brain-computer interface (BCI) and transcranial magnetic stimulation-electroencephalography (TMS-EEG). These measures provide various EEG characteristics based on different information extraction algorithms. The right panel summarizes the main EEG characteristics with respect to their potential values in classifying minimally conscious state (MCS) and vegetative state/unresponsive wakefulness syndrome (VS/UWS) (diagnostic value), outcomes prediction (prognostic value) and treatment monitoring (response to treatment). The colors identify EEG measures belonging to the main EEG techniques as indicated by the same colors in the left panel. \pm in

functional connections of recovery-conscious patients were higher than those of unrecovered patients [44]. The residual coherence in the parietal and frontoparietal regions provides strong evidence for early recovery of VS/UWS, with a high predictive sensitivity and specificity (parietal coherence at theta: sensitivity $=73 \%$, specificity $=79 \%$; frontoparietal coherence at alpha: sensitivity $=64 \%$, specificity $=77 \%$ ) [45]. Symbolic transfer entropy in the delta and alpha bands also shows a significant prognostic effect [19]. In addition, lower frontal quadratic phase self-coupling in the theta band indicates increased probability of consciousness recovery [43].

Some treatments modify the connectivity properties in DOC patients. MCS vs. VS/UWS patients show significantly different responses of frontoparietal connectivity induced by transcranial direct current stimulation or transcranial alternating current stimulation $[24,25,46,47]$. Coherence of the the 'diagnostic value' column indicate that EEG measures are larger $(+) /$ smaller $(-)$ in MCS than in VS/UWS. \pm in the 'prognostic value' column indicate that larger EEG measures correspond to better $(+) /$ worse (-) outcome. Finally, \pm in the 'response to treatment' column means that EEG measures increased/decreased during treatment. $K C C$ Kolmogorov-Chaitin complexity, wSMI weighted symbolic mutual information, $d w P L I$ debiased weighted phase lag index, STEn symbolic transfer entropy, $L P C$ late positive components, $V M I$ visuomotor integration, $V E P$ visual evoked potentials, $M M N$ mismatch negativity, TEP TMS evoked potentials, GMFP global mean field power, $P C I$ perturbational complexity index

prefrontal cortex can be modified by spinal cord stimulation [26]. And parieto-occipital connectivity can be modified by transcranial direct current stimulation [23]. Increasing spatial coherence within one cerebral hemisphere and between the hemispheres is also considered as a critical predictor of DOC patients responding to zolpidem [48].

Graph theory analysis Graph theory analysis provides an approach to quantify the features of functional neural networks. Brain networks of DOC patients show the characteristics of impairment of global information processing (network integration) and increase of local information processing (network isolation) compared with HC [49, 50]. With a decreased consciousness level, the integration of large-scale brain function networks decreases [49], but at the same time, segmentation and local efficiency increase [51]. Path length and clustering coefficient can successfully 
distinguish MCS from VS/UWS [19]. DOC patients show significantly higher local efficiency, lower modularization and higher centrality in the delta and theta band networks compared with HC [16]. Furthermore, patients misdiagnosed as VS/UWS have a similarly powerful frontal lobe brain network as MCS patients: the participation coefficient can define the existence of a hub node in the alpha network, and it is possible to clarify whether a given patient was misdiagnosed as VS/UWS based on clinical consensus [52]. Finally, a support vector machine (SVM) trained by alpha participation coefficient and delta band power could diagnose VS/UWS, MCS minus, MCS plus with $74 \%, 100 \%$ and $71 \%$ accuracy. And a SVM trained by delta modularity and clustering coefficient was able to predict outcomes of VS/ UWS and MCS with accuracy of $80 \%$ and $87 \%$, respectively [52].

Microstates Reduction of the number of EEG microstate types is associated with an altered state of consciousness (Table 3). The lack of awareness may be due to the lack of diversity of microstates in the alpha band. This highlights the importance of the fast alpha-rhythm microstate in the formation of consciousness, and also demonstrates that probability and duration of delta, theta and slow-alpha microstates are associated with unconsciousness [53]. Also, the percentage time of alpha-rhythm microstates can distinguish MCS and VS/UWS [19].

\section{Sleep patterns}

The sequential alternation of sleep stages, the presence of sleep cycles, and characteristic sleep-stage dependent EEG patterns such as sleep spindles or slow-wave oscillations are always found in healthy subjects [54]. However, they are disturbed in DOC patients (Table 4). DOC patients do not show systematic variance of sleep spindles and slowwave oscillations between day and night [55]. Moreover, a reduction in the build-up of slow-wave oscillations during sleep over parietal brain areas is commonly found in DOC patients, which is considered a characteristic topographical marker for network dysfunction [56].

Whether sleep EEG patterns are evident in VS/UWS patients is still unclear and a matter of ongoing debate. Some studies have suggested that most VS/UWS patients retain sleep behavior but do not have sleep EEG patterns (slow-wave/rapid eye movement (REM) sleep phases or synchronized regulation of slow-wave activity) associated with night-time sleep [57]. However, several other studies have suggested that VS/UWS patients can exhibit preserved sleep behaviors and EEG sleep patterns [58, 59]. Several sleep EEG components, such as spindles, slow-wave oscillations, and REM sleep are preserved in some VS/UWS patients [60-62]. Slow-wave sleep characteristics were demonstrated as the main factor that significantly correlates with the CRS-R score [63] and distinguishes between conscious patients (MCS and lock-in syndrome [LIS]) and VS/UWS [64, 65]. Some MCS patients have alternating non-REM (NREM)/REM sleep patterns with isotactic reduction in their night-time EEG [57], which is predictive of good recovery. A machine learning study showed that MCS patients are more likely to wake up during the day and have more complex patterns of sleep-wake stages at night, while VS/UWS patients do not show any accumulation of specific conditions during the day or night [66]. In addition, the number of sleep spindles and K-complexes in DOC patients increases with consciousness recovery over a 6-month follow-up [61].

\section{Evoked electroencephalogram}

\section{Event-related potentials}

\section{Auditory evoked potentials}

The majority of MCS and, to a lesser extent, VS/UWS have preserved cortical responses under auditory stimulation $[67$, 68] (Table 5). The most commonly used auditory paradigm is the oddball paradigm, which usually applies standard stimulation with a $1-\mathrm{kHz}$ tone and deviation stimulation with an $800 \mathrm{~Hz}, 1200 \mathrm{~Hz}$ or $2 \mathrm{kHz}$ tone with a period of $50-100 \mathrm{~ms}$. However, due to the low levels of consciousness and cognitive ability, pure tones may not elicit any differential responses among DOC patients of different severity. When adding more cognitive content in auditory stimulation, this can provide valuable information for detecting covert cognitive ability of behaviorally unresponsive patients. In DOC studies, the oddball experiment is usually designed with a combination of the subject's own name (SON) vs. other first name (OFN) [69].

The P300 in auditory stimulation paradigms is one of main components in DOC research. It could be detected in some MCS patients, but is less evident or absent in VS/UWS [70]. In the SON vs. OFN paradigm, both MCS and VS/ UWS show reduced modulation of spectral activity in the delta band, which indicates dissociation in the P300-related neural networks [71]. When comparing active (count SON or OFN) and passive (just listen) task conditions, P300 of some MCS patients was higher in the active than passive conditions, suggesting their capability of voluntarily complying with task instructions like HC [72]. In contrast, no P300 differences between passive and active conditions were observed in VS/UWS. In addition, the novelty P300 in active task had a wider spatial distribution than during passive listening in MCS. There was no such effect in VS/UWS [73]. Furthermore, P300 also shows prognostic value in DOC. 
Patients with a present $\mathrm{P} 300$ in some modified paradigms, such as using chord music, or calling names to the music background, tended to have better outcomes [74]. And the P300 latency, which may represent an objective index of higher-order processing integration, could predict recovery of consciousness from VS/UWS to MCS [75]. However, absence of the P300 does not exclude a possible recovery of patients.

N400 is absent in the majority of DOC patients [76]. It does not reliably distinguish VS/UWS from MCS (in three levels: listening, cognition and speech) [77]. Both MCS and VS/UWS who have a preserved N400 show increased N400 peaks and amplitudes in the middle of the forehead during inconsistent speech stimulation, but the latency of N400 in VS/UWS is longer than that in MCS [78]. The relationship of N400 with the outcome of DOC patients is noticeable: In a clinical follow-up of $53 \mathrm{VS} / \mathrm{UWS}$ and $39 \mathrm{MCS}$, patients with preserved $\mathrm{N} 400$ had a highly significant relationship with the recovery of their communication ability (in MCS: sensitivity $=40 \%$, specificity $=100 \%$; in VS/UWS: sensitivity $=60 \%$, specificity $=97 \%$ ) [79]. The highest probability of recovery $(97 \%)$ is observed for MCS with both detectable N400 and P300. In contrast, the lowest recovery chance (around 10\%) is found for VS/UWS with neither a N400 nor a P300 [80]. Another study confirmed that presence of $\mathrm{N} 400$ is a predictive marker of communication recovery with sensitivity of $50 \%$ and specificity of $90 \%$ [81].

Moreover, some other cortical responses could also be evoked by auditory stimulation in some DOC patients, including mismatch negativity (MMN) [13, 67], late positive components [81] and lateralized readiness potential [82]. Late positive components and lateralized readiness potential were demonstrated as only existing in some MCS but not VS/UWS, which may be valuable in DOC diagnosis.

\section{Visual evoked potentials}

The flash visual evoked potential (VEP) is generated when subjects observe moving balls or objects. Compared with conscious states, the VEP amplitude in DOC patients is smaller and latency is longer. Initial VEP delays have important values in predicting the long-term prognosis (up to 3 years) [83]. However, as flash VEP requires active cooperation from patients, it is almost always difficult to be properly conducted in DOC patients. Some researchers use a novel approach to address this problem by employing an associative stimulation protocol combining transcranial magnetic stimulation (TMS) with visual stimulation through transorbital alternating current stimulation. This can serve to evaluate the visuomotor integration (VMI) and visual P300 patterns in DOC patients. MCS patients exhibit preserved patterns of VMI and P300, whereas nearly all VS/UWS patients did not show significant VMI [84].

\section{Brain-computer interfaces}

Based on an external stimulus, a brain-computer interface (BCI) system directly detects brain responses rather than being limited to the subjective observation of patients and, therefore, increases objectivity and accuracy of conscious expression [85] (Table 5). Thus, BCI are used to assist clinical evaluation, especially CRS-R assessment, to obtain more accurate diagnoses. For example, for the auditory scare item in CRS-R, background noise was taken as the standard stimulus and clapping as the new stimulus. Traditionally, an assessor gives scores based on patients' behavioral responses. However, by comparing the results of CRS-R and $\mathrm{BCI}$, it was found that some patients cannot respond to the stimulus behaviorally but respond using an auditory BCI system (significant response waveforms following a loud clapping sound) $[86,87]$. Similarly, in a visual BCI study some patients show significant evoked waveforms following commands of visual fixation, but fail to get a visual fixation score in CRS-R [88]. In addition, the visual BCI system proved to have better visual tracking ability than behavioral assessment in tasks of following a moving picture or identifying pictures of specific individuals $[89,90]$. When using more complex cognitive tasks, $\mathrm{BCI}$ is sensitive to the patients' covert consciousness expression. BCI using happy/ sad emotional images shows that some DOC patients with insufficient behavioral response had significant emotional cognitive processing in the BCI system [91]. Moreover, some patients whose consciousness was detected by BCI but not behavioral assessment later have improved communication scores in their CRS-R [92]. Moreover, a gaze-independent BCI system combining auditory and visual inputs outperforms unimodal auditory-only and visual-only BCI systems. Multiple event-related potential (ERP) components, including the P300, N400 and late positive complex, could be observed only using the combined audio-visual BCI system [93]. Most patients, who respond in the audio-visual system, i.e., achieve statistically significant BCI accuracy, regain consciousness 3 months later [94].

In addition to the auditory and visual pathways, the somatosensory pathway shows important value in the DOC-BCI approach. BCI using vibratory tactile stimulation successfully identified patients without behavioral command-following but 'covert command-following' in the BCI system [95]. The patient, who responded in BCI showed a higher cerebral glucose metabolism within the language network indicative of MCS compared to other patients without responses in BCI [96]. The somatosensory discrimination BCI system also identified four VS/UWS patients who had clear task-following. The efficacy of somatosensory discrimination strongly correlates with the 6-month outcome [97]. This highlights the values of a somatosensory pathwaybased BCI system in detecting 'hidden command-following' 
in patients with lack of behavioral response. It is also promising as an auxiliary method for predicting the clinical outcome of DOC patients. When using motor imagery but not sensory stimulation, some MCS patients show capacity to operate a simple BCI-based communication system, even without any detectable volitional control of movement [98]. Three of 16 VS/UWS patients had repeatedly and reliably appropriate EEG responses to commands in a motor-imagery-based BCI [99]. In addition, most patients with cognitive-motor dissociation show evidence of following different motor imagery commands, which indicates the possibility of re-establishing communication by imagerybased BCI for such patients [100].

\section{Electroencephalogram reactivity}

EEG reactivity refers to changes of the brain electrical rhythm (frequency of EEG becoming faster or slower) or amplitude (increase or decrease) in response to external stimulation [101]. In DOC patients, EEG reactivity is more likely to occur in patients with a higher CRS-R [102]. EEG reactivity to intermittent photic stimulation and auditory stimulation is significantly higher in MCS than in VS/UWS. The preserved EEG reactivity evoked by eye opening/closing, auditory stimulation and intermittent photic stimulation has a high diagnostic specificity for the identification of patients with MCS vs. VS/UWS, while EEG reactivity to pain and tactile stimuli does not differentiate between MCS and VS/UWS [103].

\section{Transcranial magnetic stimulation-electroencephalogram}

Since transcranial magnetic stimulation-electroencephalography (TMS-EEG) does not rely on the integrity of motor pathways (in contrast to recording TMS responses by electromyography from muscle) and does not require any active participation from the patient, TMS-EEG is now considered one of the most promising techniques in the diagnosis of DOC patients (Table 6).

The first TMS-EEG work in classifying DOC patients and tracking consciousness recovery was conducted in 2012 [104]. Similar to the findings from sleep and anesthesia research $[105,106]$, a breakdown of effective connectivity, i.e., a strongly reduced propagation of the initial EEG response at the site of stimulation throughout the brain, was also found in DOC patients. Moreover, the TMS evoked EEG potentials (TEPs) are significantly different between MCS and VS/UWS. MCS exhibits low-amplitude but highfrequency TEPs that propagate widely to distant cortical regions. In contrast, VS/UWS shows TEP waveforms similar to those observed in NREM sleep and deep anesthesia in $\mathrm{HC}$, i.e. high-amplitude local EEG responses of low waveform complexity that do not propagate [104]. Another study confirmed that the TMS evoked cortical reactivity and connectivity are largely preserved in most MCS patients but not in VS/UWS patients [107]. These findings corroborate the notion that MCS patients retain extensive cortico-cortical connections for communication, which are seriously suppressed in VS/UWS patients. One proposition is that cortical
A

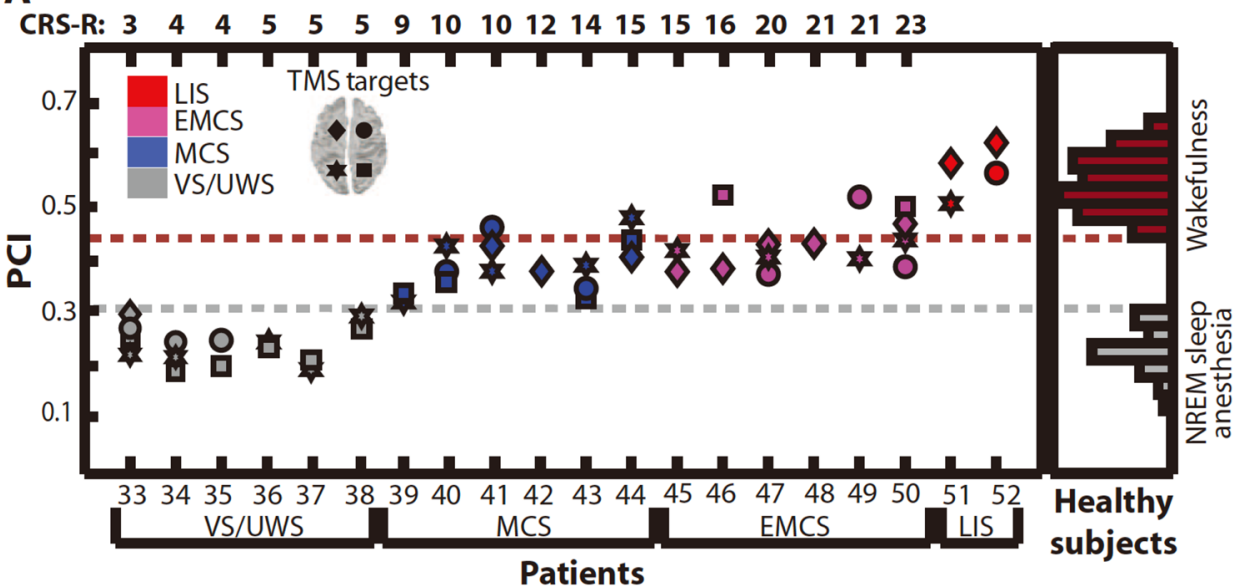

B

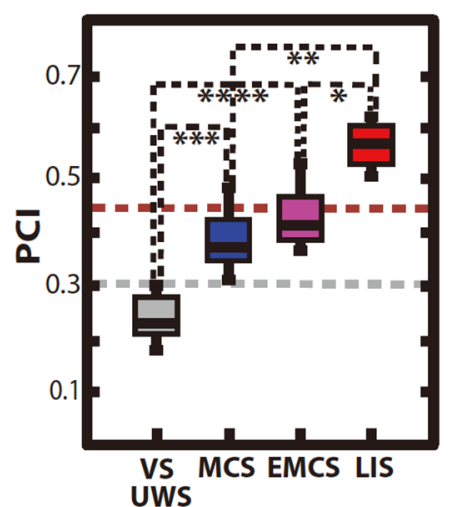

Fig. 2 Perturbational complexity index (PCI) discriminates the level of consciousness in brain-injured patients. a PCI values for 48 TMS sessions collected from 20 severely brain-injured patients (TMS was targeted to both left and right Brodmann areas 8 and 7, as indicated at top left). Right: distribution of PCI values from healthy individuals. b Box plots for PCI in brain-injured patients with the statistical significance between pairs of conditions (Linear mixed-effects models: $\left.* P=0.002, * * P=0.0001, * * * P=2 \times 10^{-5}, * * * * P=8 \times 10^{-7}\right)$. Gray and red dashed lines in (a) and (b) represent the maximum complexity observed during unconsciousness $(\mathrm{PCI}=0.31)$ and the minimum complexity observed during alert wakefulness $(\mathrm{PCI}=0.44)$ in healthy subjects, respectively (with permission, from Casali et al. [110] Sci Transl Med 5:198ra105) 
circuits fall into silence and then further impair local causal interactions and prevent the build-up of global complexity in VS/UWS patients. Such OFF periods would be similar to those detected in sleep in healthy subjects [108]. This concept was further confirmed by TEP measurements along with modification by transcranial direct current stimulation (tDCS) in DOC patients [109]. More cerebral regions could be re-excited by tDCS (increased temporal and spatial distributions of TEPs after tDCS than before) in MCS than VS/ UWS, suggesting global breakdown and silent cortexes in VS/UWS patients.

The perturbation complex index (PCI) was proposed to quantify the temporal-spatial complexity of TEPs (Fig. 2) [110]. PCI reflects the ability of integration information of cortex, which is considered as one of the key neurophysiological bases of human consciousness [111]. PCI could effectively distinguish the consciousness levels as follows: values under 0.31 as VS/UWS, $0.32-0.49$ as MCS, $0.37-0.52$ as emerged from MCS, $0.51-0.62$ as LIS and $0.44-0.67$ as awake [110]. A large sample study (43 VS/ UWS and $38 \mathrm{MCS}$ ) has measured multiple times PCI from each patient [112]. Finally, the threshold of maximum PCI reached $86.4 \%$ accuracy of identifying MCS and VS/UWS (total sensitivity $=80 \%$, specificity $=94.4 \%)$. In addition, Bodart et al. [113] combined PCI, CRS-R and FDG-PET, and demonstrated congruent data for PCI and PET in 22 of the 24 DOC patients: preserved metabolism in the frontoparietal network corresponds to PCI above 0.31. Moreover, four patients classified as VS/UWS by CRS-R but high PCI eventually showed good clinical outcome. This is consistent with other findings that most VS/UWS patients with PCI $>0.31$ recover to MCS eventually (accuracy $=73 \%$, sensitivity $=54.5 \%$, specificity $=84.2 \%$ ) [112]. Furthermore, along with a progressive clinical improvement of a MCS patient in a repetitive TMS treatment, the PCI also tended to gradually increase [114]. In summary, PCI is a diagnostic, monitoring and prognostic biomarker of high potential value in the management of DOC patients.

\section{Discussion and conclusion}

Although we still lack full knowledge about the electrophysiological foundations of human consciousness, numerous EEG studies were instrumental in developing current practice in handling DOC patients. Many EEG measures improve classification accuracy of DOC. Especially in patients who are not able to express conscious responses in behavioral assessment, bedside EEG measurements reduce rate of misdiagnosis [97, 99], and even reestablish the capability of DOC patients of communicating with the outside world [87]. At the same time, EEG measures inform physicians about neural responses to specific treatment. EEG offers the opportunity of testing the efficacy of different treatment approaches, as there is still no distinctly effective treatment strategy for DOC patients [115].

EEG studies have important implications for medicolegal decision making in DOC patients. However, the variety and complexity of EEG measures and analyses create obstacles for becoming a practical and widely applicable tool. Resting-state EEG captures spontaneous activities of neuronal assembles. However, these activities have properties of non-linear dynamics, transitions and high complexity. In addition, the signal analysis decodes information from different dimensions based on EEG amplitude, frequency, phase, time frequency, phase amplitude coupling, etc. Combined with external stimulation, EEG information becomes even more complicated. Different types of stimulation evoke responses from different neural pathways and circuits. Moreover, responses at different latencies carry different information. These complicated multitude of EEG characteristics threatens to become a burden rather than a help in the management of DOC patients. A new question need to be answered: Which one of the numerous EEG measures is the best? Some comparative studies were conducted using relatively large samples of DOC patients to test the utility of various EEG measures in diagnostic accuracy or prediction of outcome $[13,30]$. Such studies will help to sort out the most valuable consciousnessrelated EEG characteristics and facilitate their application in DOC clinics.

When using EEG for diagnostic assessment, the lack of a 'gold standard' for detection of conscious awareness is the most prominent limitation. EEG classification accuracy is extremely affected by the clinical diagnosis. Multiple studies conducted classification statistics based on diagnosis from behavioral assessment, such as CRSR. However, a significant fraction of patients is misdiagnosed based on behavioral assessments, which confounds the performance and interpretation of the EEG measures. Combining EEG with other methods, such as fluoro2-deoxy-D-glucose-positron emission tomography [52] or functional magnetic resonance imaging [100] has highlighted the potentially excellent diagnostic performance of the EEG measures. Especially, with assistance of BCI systems, it was demonstrated that many DOC patients are misdiagnosed by behavioral assessment [99]. Therefore, inconsistency between EEG classification and behavioral diagnosis should not lead to the conclusion of diagnostic inaccuracy of the EEG but rather to seek for additional diagnostic information through other neuroimaging techniques.

Current studies often show differences of EEG measures at the group level (e.g., MCI vs. VS/UWS). The group statistics cannot be used for individual diagnosis. The recently 
developed TMS-EEG technique is currently considered the most promising diagnostic method at the individual level. The relationship of TME-EEG characteristics with human consciousness was established from sleep and anesthesia research, demonstrating that ranges of the perturbational complexity index reliably classify VS/UWS, MCS and healthy individuals [112]. Determination of objective threshold values is a critical step towards building an individual diagnostic system and its clinical application.

EEG measures show potential value in predicting DOC outcome. Presence of sleep-related EEG components, such as sleep spindles, or the N400 in event-related potential recordings usually indicate good recovery $[79,116]$. However, it should be noted is that prognostic studies in DOC patients were confounded by the medical treatment strategies, nursing and complication management of the patients. For example, if MCS patients were misdiagnosed as VS/ UWS, they were more likely to be transferred to nursing homes or other facilities unable to provide best standards of medical care. Therefore, the prognostic values of EEG measures in DOC patients still await controlled, large-scale multicentre validation studies.

Finally, EEG studies in DOC patients are difficult to perform. Heterogeneity in the etiology of DOC likely imposes the problem of a lack of unifying EEG characteristics. Simple practical issues, such as motor restlessness, a characteristic feature of many MCS patients, makes EEG measurement difficult or impossible. Moreover, sequelae caused by brain injury, such as epilepsy or paroxysmal sympathetic hyperactivity, may contaminate the EEG signal. In addition, EEG characteristics, which might show diagnostic or prognostic utility in some studies will likely not always perform well in real-world clinical applications due to limited sample sizes and specific patient characteristics in the studies. Despite these limitations, the current review still identified some specific EEG characteristics with consistently reliable performance across studies in identifying the consciousness level and predicting outcome of DOC patients, such as restingstate alpha power in MCS vs. VS/UWS classification [11, 30], N400 in MCS recovery prediction [79, 80], and PCI (from TMS-EEG) in both individual diagnosis and prognosis $[110,112]$. Moreover, machine learning trained by comprehensive EEG characteristics, including indexes derived from different information dimensions, could achieve high levels of accuracy in diagnosis and prognosis of DOC patients [30, 52].

Despite all difficulty and immaturity, this review has provided manifold evidence that the EEG can assess the dysfunctional brain networks of DOC patients, resulting in relevant improvement in diagnostic accuracy, and opening up the opportunity of monitoring treatment effects and predicting long-term outcome. This will help the professional handling of DOC patients.
Funding Open Access funding enabled and organized by Projekt DEAL. This work was supported by the Alexander von Humboldt-Stiftung (1203399-CHN-HFST-P); National Natural Science Foundation of China (61901155); Medicine and Health Science and Technology Project of Zhejiang Province (2019RC254).

\section{Compliance with ethical standards}

Conflicts of interests U.Z. has received a grant from Janssen Pharmaceutica NV to support conduction of this work. In addition, he has received grants from European Research Council (ERC), German Research Foundation (DFG), German Federal Ministry of Education and Research (BMBF), Bristol Myers Squibb, Servier, Biogen Idec $\mathrm{GmbH}$, and personal fees from Bayer Vital GmbH, Pfizer GmbH, CorTec GmbH, all outside of this work. Y.B. and Y.L. declare that they have no conflict of interest.

Open Access This article is licensed under a Creative Commons Attribution 4.0 International License, which permits use, sharing, adaptation, distribution and reproduction in any medium or format, as long as you give appropriate credit to the original author(s) and the source, provide a link to the Creative Commons licence, and indicate if changes were made. The images or other third party material in this article are included in the article's Creative Commons licence, unless indicated otherwise in a credit line to the material. If material is not included in the article's Creative Commons licence and your intended use is not permitted by statutory regulation or exceeds the permitted use, you will need to obtain permission directly from the copyright holder. To view a copy of this licence, visit http://creativecommons.org/licenses/by/4.0/.

\section{References}

1. Giacino JT, Fins JJ, Laureys S, Schiff ND (2014) Disorders of consciousness after acquired brain injury: the state of the science. Nat Rev Neurol 10(2):99-114. https://doi.org/10.1038/ nrneurol.2013.279

2. Schiff ND, Plum F (2000) The role of arousal and "gating" systems in the neurology of impaired consciousness. J Clin Neurophysiol 17(5):438-452. https://doi.org/10.1097/00004691-20000 9000-00002

3. Marsden C (1981) The diagnosis of stupor and coma ( $3^{\text {rd }}$ edn). J Neurol Neurosurg Psychiatry 44(3):270-271

4. Laureys S, Celesia GG, Cohadon F, Lavrijsen J, Leon-Carrion J, Sannita WG, Sazbon L, Schmutzhard E, von Wild KR, Zeman A, Dolce G, European Task Force on Disorders of C (2010) Unresponsive wakefulness syndrome: a new name for the vegetative state or apallic syndrome. BMC Med 8:68. https://doi. org/10.1186/1741-7015-8-68

5. Giacino JT, Ashwal S, Childs N, Cranford R, Jennett B, Katz DI, Kelly JP, Rosenberg JH, Whyte J, Zafonte RD, Zasler ND (2002) The minimally conscious state: definition and diagnostic criteria. Neurology 58(3):349-353. https://doi.org/10.1212/wnl.58.3.349

6. Giacino JT, Kalmar K, Whyte J (2004) The JFK Coma Recovery Scale-Revised: measurement characteristics and diagnostic utility. Arch Phys Med Rehabil 85(12):2020-2029. https://doi. org/10.1016/j.apmr.2004.02.033

7. Giacino JT, Schnakers C, Rodriguez-Moreno D, Kalmar K, Schiff $\mathrm{N}$, Hirsch J (2009) Behavioral assessment in patients with disorders of consciousness: gold standard or fool's gold? Prog Brain Res 177:33-48. https://doi.org/10.1016/S0079-6123(09)17704 -X 
8. Schnakers C, Vanhaudenhuyse A, Giacino J, Ventura M, Boly M, Majerus S, Moonen G, Laureys S (2009) Diagnostic accuracy of the vegetative and minimally conscious state: clinical consensus versus standardized neurobehavioral assessment. BMC Neurol 9:35. https://doi.org/10.1186/1471-2377-9-35

9. Klimesch W (1999) EEG alpha and theta oscillations reflect cognitive and memory performance: a review and analysis. Brain Res Brain Res Rev 29(2-3):169-195. https://doi.org/10.1016/ s0165-0173(98)00056-3

10. Busch NA, VanRullen R (2010) Spontaneous EEG oscillations reveal periodic sampling of visual attention. Proc Natl Acad Sci USA 107(37):16048-16053. https://doi.org/10.1073/pnas.10048 01107

11. Rossi Sebastiano D, Panzica F, Visani E, Rotondi F, Scaioli V, Leonardi M, Sattin D, D'Incerti L, Parati E, Ferini Strambi L, Franceschetti S (2015) Significance of multiple neurophysiological measures in patients with chronic disorders of consciousness. Clin Neurophysiol 126(3):558-564. https://doi.org/10.1016/j. clinph.2014.07.004

12. Lechinger J, Bothe K, Pichler G, Michitsch G, Donis J, Klimesch W, Schabus M (2013) CRS-R score in disorders of consciousness is strongly related to spectral EEG at rest. J Neurol 260(9):23482356. https://doi.org/10.1007/s00415-013-6982-3

13. Sitt JD, King J-R, El Karoui I, Rohaut B, Faugeras F, Gramfort A, Cohen L, Sigman M, Dehaene S, Naccache L (2014) Large scale screening of neural signatures of consciousness in patients in a vegetative or minimally conscious state. Brain 137(8):22582270. https://doi.org/10.1093/brain/awu141

14. Piarulli A, Bergamasco M, Thibaut A, Cologan V, Gosseries O, Laureys S (2016) EEG ultradian rhythmicity differences in disorders of consciousness during wakefulness. J Neurol 263(9):1746-1760. https://doi.org/10.1007/s00415-016-8196-y

15. Naro A, Bramanti A, Leo A, Cacciola A, Manuli A, Bramanti P, Calabro RS (2018) Shedding new light on disorders of consciousness diagnosis: the dynamic functional connectivity. Cortex 103:316-328. https://doi.org/10.1016/j.cortex.2018.03.029

16. Chennu S, Finoia P, Kamau E, Allanson J, Williams GB, Monti MM, Noreika V, Arnatkeviciute A, Canales-Johnson A, Olivares F, Cabezas-Soto D, Menon DK, Pickard JD, Owen AM, Bekinschtein TA (2014) Spectral signatures of reorganised brain networks in disorders of consciousness. PLoS Comput Biol 10(10):e1003887. https://doi.org/10.1371/journal.pcbi.1003887

17. Leon-Carrion J, Martin-Rodriguez JF, Damas-Lopez J, Barrosoy Martin JM, Dominguez-Morales MR (2008) Brain function in the minimally conscious state: a quantitative neurophysiological study. Clin Neurophysiol 119(7):1506-1514. https://doi. org/10.1016/j.clinph.2008.03.030

18. Naro A, Bramanti P, Leo A, Cacciola A, Bramanti A, Manuli A, Calabro RS (2016) Towards a method to differentiate chronic disorder of consciousness patients' awareness: the low-resolution brain electromagnetic tomography analysis. J Neurol Sci 368:178-183. https://doi.org/10.1016/j.jns.2016.07.016

19. Stefan S, Schorr B, Lopez-Rolon A, Kolassa IT, Shock JP, Rosenfelder M, Heck S, Bender A (2018) Consciousness indexing and outcome prediction with resting-state EEG in severe disorders of consciousness. Brain Topogr 31(5):848-862. https://doi. org/10.1007/s10548-018-0643-x

20. Lehembre R, Bruno MA, Vanhaudenhuyse A, Chatelle C, Cologan V, Leclercq Y, Soddu A, Macq B, Laureys S, Noirhomme Q (2012) Resting-state EEG study of comatose patients: a connectivity and frequency analysis to find differences between vegetative and minimally conscious states. Funct Neurol 27(1):41-47

21. Chennu S, O'Connor S, Adapa R, Menon DK, Bekinschtein TA (2016) Brain connectivity dissociates responsiveness from drug exposure during propofol-induced transitions of consciousness.
PLoS Comput Biol 12(1):e1004669. https://doi.org/10.1371/ journal.pcbi.1004669

22. Babiloni C, Sara M, Vecchio F, Pistoia F, Sebastiano F, Onorati P, Albertini G, Pasqualetti P, Cibelli G, Buffo P, Rossini PM (2009) Cortical sources of resting-state alpha rhythms are abnormal in persistent vegetative state patients. Clin Neurophysiol 120(4):719-729. https://doi.org/10.1016/j.clinph.2009.02.157

23. Hermann B, Raimondo F, Hirsch L, Huang Y, Denis-Valente M, Perez P, Engemann D, Faugeras F, Weiss N, Demeret S, Rohaut B, Parra LC, Sitt JD, Naccache L (2020) Combined behavioral and electrophysiological evidence for a direct cortical effect of prefrontal tDCS on disorders of consciousness. Sci Rep 10(1):4323. https://doi.org/10.1038/s41598-020-61180-2

24. Naro A, Bramanti P, Leo A, Russo M, Calabro RS (2016) Transcranial alternating current stimulation in patients with chronic disorder of consciousness: a possible way to cut the diagnostic gordian knot? Brain Topogr 29(4):623-644. https://doi. org/10.1007/s10548-016-0489-z

25. Naro A, Russo M, Leo A, Cannavo A, Manuli A, Bramanti A, Bramanti P, Calabro RS (2016) Cortical connectivity modulation induced by cerebellar oscillatory transcranial direct current stimulation in patients with chronic disorders of consciousness: a marker of covert cognition? Clin Neurophysiol 127(3):18451854. https://doi.org/10.1016/j.clinph.2015.12.010

26. Bai Y, Xia X, Li X, Wang Y, Yang Y, Liu Y, Liang Z, He J (2017) Spinal cord stimulation modulates frontal delta and gamma in patients of minimally consciousness state. Neuroscience 346:247-254. https://doi.org/10.1016/j.neuroscien ce.2017.01.036

27. Coleman MR, Menon DK, Fryer TD, Pickard JD (2005) Neurometabolic coupling in the vegetative and minimally conscious states: preliminary findings. J Neurol Neurosurg Psychiatry 76(3):432-434. https://doi.org/10.1136/jnnp.2004.045930

28. Wu DY, Cai G, Yuan Y, Liu L, Li GQ, Song WQ, Wang MB (2011) Application of nonlinear dynamics analysis in assessing unconsciousness: a preliminary study. Clin Neurophysiol 122(3):490-498. https://doi.org/10.1016/j.clinph.2010.05.036

29. Sara M, Pistoia F, Pasqualetti P, Sebastiano F, Onorati P, Rossini PM (2011) Functional isolation within the cerebral cortex in the vegetative state: a nonlinear method to predict clinical outcomes. Neurorehabil Neural Repair 25(1):35-42. https://doi. org/10.1177/1545968310378508

30. Engemann DA, Raimondo F, King JR, Rohaut B, Louppe G, Faugeras F, Annen J, Cassol H, Gosseries O, Fernandez-Slezak D, Laureys S, Naccache L, Dehaene S, Sitt JD (2018) Robust EEG-based cross-site and cross-protocol classification of states of consciousness. Brain 141(11):3179-3192. https://doi. org/10.1093/brain/awy251

31. Wang Y, Bai Y, Xia X, Yang Y, He J, Li X (2019) Spinal cord stimulation modulates complexity of neural activities in patients with disorders of consciousness. Int J Neurosci. https://doi. org/10.1080/00207454.2019.1702543

32. Gosseries O, Schnakers C, Ledoux D, Vanhaudenhuyse A, Bruno MA, Demertzi A, Noirhomme Q, Lehembre R, Damas P, Goldman S, Peeters E, Moonen G, Laureys S (2011) Automated EEG entropy measurements in coma, vegetative state/unresponsive wakefulness syndrome and minimally conscious state. Funct Neurol 26(1):25-30

33. Schnakers C, Ledoux D, Majerus S, Damas P, Damas F, Lambermont B, Lamy M, Boly M, Vanhaudenhuyse A, Moonen G, Laureys S (2008) Diagnostic and prognostic use of bispectral index in coma, vegetative state and related disorders. Brain Inj 22(12):926-931. https://doi.org/10.1080/02699050802530565

34. Wu DY, Cai G, Zorowitz RD, Yuan Y, Wang J, Song WQ (2011) Measuring interconnection of the residual cortical functional islands in persistent vegetative state and minimal conscious state 
with EEG nonlinear analysis. Clin Neurophysiol 122(10):19561966. https://doi.org/10.1016/j.clinph.2011.03.018

35. Cavinato M, Genna C, Manganotti P, Formaggio E, Storti SF, Campostrini S, Arcaro C, Casanova E, Petrone V, Piperno R, Piccione F (2015) Coherence and consciousness: study of fronto-parietal gamma synchrony in patients with disorders of consciousness. Brain Topogr 28(4):570-579. https://doi. org/10.1007/s10548-014-0383-5

36. Laureys $S$ (2005) The neural correlate of (un)awareness: lessons from the vegetative state. Trends Cogn Sci 9(12):556-559. https ://doi.org/10.1016/j.tics.2005.10.010

37. Laureys S, Goldman S, Phillips C, Van Bogaert P, Aerts J, Luxen A, Franck G, Maquet P (1999) Impaired effective cortical connectivity in vegetative state: preliminary investigation using PET. Neuroimage 9(4):377-382. https://doi.org/10.1006/ nimg.1998.0414

38. Leon-Carrion J, Leon-Dominguez U, Pollonini L, Wu MH, Frye RE, Dominguez-Morales MR, Zouridakis G (2012) Synchronization between the anterior and posterior cortex determines consciousness level in patients with traumatic brain injury (TBI). Brain Res 1476:22-30. https://doi.org/10.1016/j.brain res.2012.03.055

39. Davey M, Victor J, Schiff N (2000) Power spectra and coherence in the EEG of a vegetative patient with severe asymmetric brain damage. Clin Neurophysiol 111:1949-1954

40. Thul A, Lechinger J, Donis J, Michitsch G, Pichler G, Kochs EF, Jordan D, Ilg R, Schabus M (2016) EEG entropy measures indicate decrease of cortical information processing in Disorders of Consciousness. Clin Neurophysiol 127(2):1419-1427. https:// doi.org/10.1016/j.clinph.2015.07.039

41. Pollonini L, Pophale S, Situ N, Wu MH, Frye RE, Leon-Carrion $\mathrm{J}$, Zouridakis $\mathrm{G}$ (2010) Information communication networks in severe traumatic brain injury. Brain Topogr 23(2):221-226. https ://doi.org/10.1007/s10548-010-0139-9

42. King JR, Sitt JD, Faugeras F, Rohaut B, El Karoui I, Cohen L, Naccache L, Dehaene S (2013) Information sharing in the brain indexes consciousness in noncommunicative patients. Curr Biol 23(19):1914-1919. https://doi.org/10.1016/j.cub.2013.07.075

43. Bai Y, Xia X, Wang Y, He J, Li X (2019) Electroencephalography quadratic phase self-coupling correlates with consciousness states and restoration in patients with disorders of consciousness. Clin Neurophysiol 130(8):1235-1242. https://doi.org/10.1016/j. clinph.2019.04.710

44. Fingelkurts AA, Fingelkurts AA, Bagnato S, Boccagni C, Galardi G (2013) Prognostic value of resting-state electroencephalography structure in disentangling vegetative and minimally conscious states: a preliminary study. Neurorehabil Neural Repair 27(4):345-354. https://doi.org/10.1177/1545968312469836

45. Schorr B, Schlee W, Arndt M, Bender A (2016) Coherence in resting-state EEG as a predictor for the recovery from unresponsive wakefulness syndrome. J Neurol 263(5):937-953. https:// doi.org/10.1007/s00415-016-8084-5

46. Bai Y, Xia X, Wang Y, Guo Y, Yang Y, He J, Li X (2018) Frontoparietal coherence response to tDCS modulation in patients with disorders of consciousness. Int J Neurosci 128(7):587-594. https ://doi.org/10.1080/00207454.2017.1403440

47. Cavinato M, Genna C, Formaggio E, Gregorio C, Storti SF, Manganotti P, Casanova E, Piperno R, Piccione F (2019) Behavioural and electrophysiological effects of tDCS to prefrontal cortex in patients with disorders of consciousness. Clin Neurophysiol 130(2):231-238. https://doi.org/10.1016/j.clinph.2018.10.018

48. Williams ST, Conte MM, Goldfine AM, Noirhomme Q, Gosseries O, Thonnard M, Beattie B, Hersh J, Katz DI, Victor JD, Laureys S, Schiff ND (2013) Common resting brain dynamics indicate a possible mechanism underlying zolpidem response in severe brain injury. Elife 2:e01157. https://doi.org/10.7554/ eLife.01157

49. Rizkallah J, Annen J, Modolo J, Gosseries O, Benquet P, Mortaheb S, Amoud H, Cassol H, Mheich A, Thibaut A, Chatelle C, Hassan M, Panda R, Wendling F, Laureys S (2019) Decreased integration of EEG source-space networks in disorders of consciousness. Neuroimage Clin 23:101841. https:// doi.org/10.1016/j.nicl.2019.101841

50. Cai L, Wang J, Guo Y, Lu M, Dong Y, Wei X (2020) Altered inter-frequency dynamics of brain networks in disorder of consciousness. J Neural Eng. https://doi.org/10.1088/1741-2552/ $\mathrm{ab} 8 \mathrm{~b} 2 \mathrm{c}$

51. Cacciola A, Naro A, Milardi D, Bramanti A, Malatacca L, Spitaleri M, Leo A, Muscoloni A, Cannistraci CV, Bramanti P, Calabro RS, Anastasi GP (2019) Functional brain network topology discriminates between patients with minimally conscious state and unresponsive wakefulness syndrome. J Clin Med 8(3):306. https://doi.org/10.3390/jcm8030306 (ARTN306)

52. Chennu S, Annen J, Wannez S, Thibaut A, Chatelle C, Cassol H, Martens G, Schnakers C, Gosseries O, Menon D, Laureys $S$ (2017) Brain networks predict metabolism, diagnosis and prognosis at the bedside in disorders of consciousness. Brain 140(8):2120-2132. https://doi.org/10.1093/brain/awx163

53. Fingelkurts AA, Fingelkurts AA, Bagnato S, Boccagni C, Galardi G (2012) EEG oscillatory states as neuro-phenomenology of consciousness as revealed from patients in vegetative and minimally conscious states. Conscious Cogn 21(1):149-169. https:// doi.org/10.1016/j.concog.2011.10.004

54. Dijk DJ, Hayes B, Czeisler CA (1993) Dynamics of electroencephalographic sleep spindles and slow wave activity in men: effect of sleep deprivation. Brain Res 626(1-2):190-199. https ://doi.org/10.1016/0006-8993(93)90579-c

55. Wislowska M, Del Giudice R, Lechinger J, Wielek T, Heib DPJ, Pitiot A, Pichler G, Michitsch G, Donis J, Schabus M (2017) Night and day variations of sleep in patients with disorders of consciousness. Sci Rep 7(1):266. https://doi.org/10.1038/s4159 8-017-00323-4

56. Mouthon AL, van Hedel HJA, Meyer-Heim A, Kurth S, Ringli M, Pugin F, Huber R (2016) High-density electroencephalographic recordings during sleep in children with disorders of consciousness. Neuroimage Clin 11:468-475. https://doi.org/10.1016/j. nicl.2016.03.012

57. Landsness E, Bruno MA, Noirhomme Q, Riedner B, Gosseries O, Schnakers C, Massimini M, Laureys S, Tononi G, Boly M (2011) Electrophysiological correlates of behavioural changes in vigilance in vegetative state and minimally conscious state. Brain 134(Pt 8):2222-2232. https://doi.org/10.1093/brain/awr152

58. Oksenberg A, Gordon C, Arons E, Sazbon L (2001) Phasic activities of rapid eye movement sleep in vegetative state patients. Sleep 24(6):703-706. https://doi.org/10.1093/sleep/24.6.703

59. Isono M, Wakabayashi Y, Fujiki MM, Kamida T, Kobayashi H (2002) Sleep cycle in patients in a state of permanent unconsciousness. Brain Inj 16(8):705-712. https://doi. org/10.1080/02699050210127303

60. Forgacs PB, Conte MM, Fridman EA, Voss HU, Victor JD, Schiff ND (2014) Preservation of electroencephalographic organization in patients with impaired consciousness and imaging-based evidence of command-following. Ann Neurol 76(6):869-879. https://doi.org/10.1002/ana.24283

61. Cologan V, Drouot X, Parapatics S, Delorme A, Gruber G, Moonen G, Laureys S (2013) Sleep in the unresponsive wakefulness syndrome and minimally conscious state. J Neurotrauma 30(5):339-346. https://doi.org/10.1089/neu.2012.2654

62. Pavlov YG, Gais S, Muller F, Schonauer M, Schapers B, Born J, Kotchoubey B (2017) Night sleep in patients with vegetative 
state. J Sleep Res 26(5):629-640. https://doi.org/10.1111/ jsr. 12524

63. Rossi Sebastiano D, Visani E, Panzica F, Sattin D, Bersano A, Nigri A, Ferraro S, Parati E, Leonardi M, Franceschetti S (2018) Sleep patterns associated with the severity of impairment in a large cohort of patients with chronic disorders of consciousness. Clin Neurophysiol 129(3):687-693. https://doi.org/10.1016/j. clinph.2017.12.012

64. Malinowska U, Chatelle C, Bruno MA, Noirhomme Q, Laureys S, Durka PJ (2013) Electroencephalographic profiles for differentiation of disorders of consciousness. Biomed Eng Online 12(1):109. https://doi.org/10.1186/1475-925X-12-109

65. Zieleniewska M, Duszyk A, Rozanski P, Pietrzak M, Bogotko M, Durka P (2019) Parametric description of EEG profiles for assessment of sleep architecture in disorders of consciousness. Int J Neural Syst 29(3):1850049. https://doi.org/10.1142/S0129 065718500491

66. Wielek T, Lechinger J, Wislowska M, Blume C, Ott P, Wegenkittl S, Del Giudice R, Heib DPJ, Mayer HA, Laureys S, Pichler G, Schabus M (2018) Sleep in patients with disorders of consciousness characterized by means of machine learning. PLoS ONE 13(1):e0190458. https://doi.org/10.1371/journal.pone.0190458

67. Kotchoubey B, Lang S, Mezger G, Schmalohr D, Schneck M, Semmler A, Bostanov V, Birbaumer N (2005) Information processing in severe disorders of consciousness: vegetative state and minimally conscious state. Clin Neurophysiol 116(10):24412453. https://doi.org/10.1016/j.clinph.2005.03.028

68. Fischer C, Luaute J, Morlet D (2010) Event-related potentials (MMN and novelty P3) in permanent vegetative or minimally conscious states. Clin Neurophysiol 121(7):1032-1042. https:// doi.org/10.1016/j.clinph.2010.02.005

69. Perrin F, Schnakers C, Schabus M, Degueldre C, Goldman S, Bredart S, Faymonville ME, Lamy M, Moonen G, Luxen A, Maquet P, Laureys S (2006) Brain response to one's own name in vegetative state, minimally conscious state, and locked-in syndrome. Arch Neurol 63(4):562-569. https://doi.org/10.1001/ archneur.63.4.562

70. Li R, Song WQ, Du JB, Huo S, Shan GX (2015) Connecting the P300 to the diagnosis and prognosis of unconscious patients. Neural Regen Res 10(3):473-480. https://doi.org/10.4103/16735374.153699

71. Rivera-Lillo G, Rojas-Libano D, Burgos P, Egana JI, Chennu S, Maldonado PE (2018) Reduced delta-band modulation underlies the loss of P300 responses in disorders of consciousness. Clin Neurophysiol 129(12):2613-2622. https://doi.org/10.1016/j.clinp h.2018.09.104

72. Schnakers C, Perrin F, Schabus M, Majerus S, Ledoux D, Damas P, Boly M, Vanhaudenhuyse A, Bruno M, Moonen G, Laureys S (2008) Voluntary brain processing in disorders of consciousness. Neurology 71(20): 1614-1620

73. Risetti M, Formisano R, Toppi J, Quitadamo LR, Bianchi L, Astolfi L, Cincotti F, Mattia D (2013) On ERPs detection in disorders of consciousness rehabilitation. Front Hum Neurosci 7:775. https://doi.org/10.3389/fnhum.2013.00775

74. Castro M, Tillmann B, Luaute J, Corneyllie A, Dailler F, AndreObadia N, Perrin F (2015) Boosting cognition with music in patients with disorders of consciousness. Neurorehabil Neural Repair 29(8):734-742. https://doi.org/10.1177/1545968314 565464

75. Cavinato M, Volpato C, Silvoni S, Sacchetto M, Merico A, Piccione F (2011) Event-related brain potential modulation in patients with severe brain damage. Clin Neurophysiol 122(4):719-724. https://doi.org/10.1016/j.clinph.2010.08.024

76. Erlbeck H, Real RG, Kotchoubey B, Mattia D, Bargak J, Kubler A (2017) Basic discriminative and semantic processing in patients in the vegetative and minimally conscious state.
Int J Psychophysiol 113:8-16. https://doi.org/10.1016/j.ijpsy cho.2016.12.012

77. Beukema S, Gonzalez-Lara LE, Finoia P, Kamau E, Allanson J, Chennu S, Gibson RM, Pickard JD, Owen AM, Cruse D (2016) A hierarchy of event-related potential markers of auditory processing in disorders of consciousness. Neuroimage Clin 12:359371. https://doi.org/10.1016/j.nicl.2016.08.003

78. Balconi M, Arangio R (2015) The relationship between coma near coma, disability ratings, and event-related potentials in patients with disorders of consciousness: a semantic association task. Appl Psychophysiol Biofeedback 40(4):327-337. https:// doi.org/10.1007/s10484-015-9304-y

79. Steppacher I, Eickhoff S, Jordanov T, Kaps M, Witzke W, Kissler J (2013) N400 predicts recovery from disorders of consciousness. Ann Neurol 73(5):594-602. https://doi.org/10.1002/ana.23835

80. Steppacher I, Fuchs P, Kaps M, Nussbeck FW, Kissler J (2020) A tree of life? Multivariate logistic outcome-prediction in disorders of consciousness. Brain Inj 34(3):399-406. https://doi. org/10.1080/02699052.2019.1695289

81. Rohaut B, Faugeras F, Chausson N, King JR, Karoui IE, Cohen L, Naccache L (2015) Probing ERP correlates of verbal semantic processing in patients with impaired consciousness. Neuropsychologia 66:279-292. https://doi.org/10.1016/j.neuropsychologi a.2014.10.014

82. Sergent C, Faugeras F, Rohaut B, Perrin F, Valente M, TallonBaudry C, Cohen L, Naccache L (2017) Multidimensional cognitive evaluation of patients with disorders of consciousness using EEG: a proof of concept study. Neuroimage Clin 13:455-469. https://doi.org/10.1016/j.nicl.2016.12.004

83. Wijnen VJ, Eilander HJ, de Gelder B, van Boxtel GJ (2014) Visual processing during recovery from vegetative state to consciousness: comparing behavioral indices to brain responses. Neurophysiol Clin 44(5):457-469. https://doi.org/10.1016/j. neucli.2014.08.008

84. Naro A, Leo A, Buda A, Manuli A, Bramanti A, Bramanti P, Calabro RS (2016) Do you see me? The role of visual fixation in chronic disorders of consciousness differential diagnosis. Brain Res 1653:59-66. https://doi.org/10.1016/j.brainres.2016.10.015

85. Wolpaw JR, Birbaumer N, McFarland DJ, Pfurtscheller G, Vaughan TM (2002) Brain-computer interfaces for communication and control. Clin Neurophysiol 113(6):767-791. https://doi. org/10.1016/s1388-2457(02)00057-3

86. Xiao J, Xie Q, He Y, Yu T, Lu S, Huang N, Yu R, Li Y (2016) An auditory BCI system for assisting CRS-R behavioral assessment in patients with disorders of consciousness. Sci Rep 6:32917. https://doi.org/10.1038/srep32917

87. Lule D, Noirhomme Q, Kleih SC, Chatelle C, Halder S, Demertzi A, Bruno MA, Gosseries O, Vanhaudenhuyse A, Schnakers C, Thonnard M, Soddu A, Kubler A, Laureys S (2013) Probing command following in patients with disorders of consciousness using a brain-computer interface. Clin Neurophysiol 124(1):101106. https://doi.org/10.1016/j.clinph.2012.04.030

88. Xiao J, Pan J, He Y, Xie Q, Yu T, Huang H, Lv W, Zhang J, Yu R, Li Y (2018) Visual fixation assessment in patients with disorders of consciousness based on brain-computer interface. Neurosci Bull 34(4):679-690. https://doi.org/10.1007/s12264-018-0257-z

89. Xiao J, Xie Q, Lin Q, Yu T, Yu R, Li Y (2018) Assessment of visual pursuit in patients with disorders of consciousness based on a brain-computer interface. IEEE Trans Neural Syst Rehabil Eng 26(6):1141-1151. https://doi.org/10.1109/TNSRE.2018.2835813

90. Pan J, Xie Q, He Y, Wang F, Di H, Laureys S, Yu R, Li Y (2014) Detecting awareness in patients with disorders of consciousness using a hybrid brain-computer interface. J Neural Eng 11(5):056007. https://doi.org/10.1088/1741-2560/11/5/056007

91. Pan J, Xie Q, Huang H, He Y, Sun Y, Yu R, Li Y (2018) Emotion-related consciousness detection in patients with disorders of 
consciousness through an EEG-based BCI system. Front Hum Neurosci 12:198. https://doi.org/10.3389/fnhum.2018.00198

92. Wang F, He Y, Qu J, Xie Q, Lin Q, Ni X, Chen Y, Pan J, Laureys S, Yu R, Li Y (2017) Enhancing clinical communication assessments using an audiovisual BCI for patients with disorders of consciousness. J Neural Eng 14(4):046024. https://doi. org/10.1088/1741-2552/aa6c31

93. Xie Q, Pan J, Chen Y, He Y, Ni X, Zhang J, Wang F, Li Y, Yu R (2018) A gaze-independent audiovisual brain-computer Interface for detecting awareness of patients with disorders of consciousness. BMC Neurol 18(1):144. https://doi.org/10.1186/ s12883-018-1144-y

94. Pan J, Xie Q, Qin P, Chen Y, He Y, Huang H, Wang F, Ni X, Cichocki A, Yu R, Li Y (2020) Prognosis for patients with cognitive motor dissociation identified by brain-computer interface. Brain 143(4):1177-1189. https://doi.org/10.1093/brain/awaa026

95. Guger C, Spataro R, Pellas F, Allison BZ, Heilinger A, Ortner R, Cho W, Xu R, La Bella V, Edlinger G, Annen J, Mandala G, Chatelle C, Laureys S (2018) Assessing command-following and communication with vibro-tactile $\mathrm{P} 300$ brain-computer interface tools in patients with unresponsive wakefulness syndrome. Front Neurosci 12:423. https://doi.org/10.3389/fnins.2018.00423

96. Annen J, Blandiaux S, Lejeune N, Bahri MA, Thibaut A, Cho W, Guger C, Chatelle C, Laureys S (2018) BCI performance and brain metabolism profile in severely brain-injured patients without response to command at bedside. Front Neurosci 12:370. https://doi.org/10.3389/fnins.2018.00370

97. Spataro R, Heilinger A, Allison B, De Cicco D, Marchese S, Gregoretti C, La Bella V, Guger C (2018) Preserved somatosensory discrimination predicts consciousness recovery in unresponsive wakefulness syndrome. Clin Neurophysiol 129(6):11301136. https://doi.org/10.1016/j.clinph.2018.02.131

98. Coyle D, Stow J, McCreadie K, McElligott J, Carroll A (2015) Sensorimotor modulation assessment and brain-computer interface training in disorders of consciousness. Arch Phys Med Rehabil 96(3 Suppl):S62-70. https://doi.org/10.1016/j. apmr.2014.08.024

99. Cruse D, Chennu S, Chatelle C, Bekinschtein TA, FernandezEspejo D, Pickard JD, Laureys S, Owen AM (2011) Bedside detection of awareness in the vegetative state: a cohort study. Lancet 378(9809):2088-2094. https://doi.org/10.1016/S0140 $-6736(11) 61224-5$

100. Curley WH, Forgacs PB, Voss HU, Conte MM, Schiff ND (2018) Characterization of EEG signals revealing covert cognition in the injured brain. Brain 141(5):1404-1421. https://doi.org/10.1093/ brain/awy070

101. Young GB (2000) The EEG in Coma. J Clin Neurophysiol 17(5):473-485

102. Bagnato S, Boccagni C, Sant'Angelo A, Prestandrea C, Mazzilli $R$, Galardi G (2015) EEG predictors of outcome in patients with disorders of consciousness admitted for intensive rehabilitation. Clin Neurophysiol 126(5):959-966. https://doi.org/10.1016/j. clinph.2014.08.005

103. Estraneo A, Loreto V, Guarino I, Boemia V, Paone G, Moretta $\mathrm{P}$, Trojano L (2016) Standard EEG in diagnostic process of prolonged disorders of consciousness. Clin Neurophysiol 127(6):2379-2385. https://doi.org/10.1016/j.clinph.2016.03.021

104. Rosanova M, Gosseries O, Casarotto S, Boly M, Casali AG, Bruno MA, Mariotti M, Boveroux P, Tononi G, Laureys S, Massimini M (2012) Recovery of cortical effective connectivity and recovery of consciousness in vegetative patients. Brain $135(\mathrm{Pt}$ 4):1308-1320. https://doi.org/10.1093/brain/awr340

105. Massimini M, Ferrarelli F, Huber R, Esser SK, Singh H, Tononi G (2005) Breakdown of cortical effective connectivity during sleep. Science 309(5744):2228-2232. https://doi.org/10.1126/ science. 1117256
106. Ferrarelli F, Massimini M, Sarasso S, Casali A, Riedner BA, Angelini G, Tononi G, Pearce RA (2010) Breakdown in cortical effective connectivity during midazolam-induced loss of consciousness. Proc Natl Acad Sci USA 107(6):2681-2686. https:// doi.org/10.1073/pnas.0913008107

107. Ragazzoni A, Pirulli C, Veniero D, Feurra M, Cincotta M, Giovannelli F, Chiaramonti R, Lino M, Rossi S, Miniussi C (2013) Vegetative versus minimally conscious states: a study using TMS-EEG, sensory and event-related potentials. PLoS ONE 8(2):e57069. https://doi.org/10.1371/journal.pone.0057069

108. Rosanova M, Fecchio M, Casarotto S, Sarasso S, Casali AG, Pigorini A, Comanducci A, Seregni F, Devalle G, Citerio G, Bodart O, Boly M, Gosseries O, Laureys S, Massimini M (2018) Sleep-like cortical OFF-periods disrupt causality and complexity in the brain of unresponsive wakefulness syndrome patients. Nat Commun 9(1):4427. https://doi.org/10.1038/s41467-018-06871 $-1$

109. Bai Y, Xia X, Kang J, Yang Y, He J, Li X (2017) TDCS modulates cortical excitability in patients with disorders of consciousness. Neuroimage Clin 15:702-709. https://doi.org/10.1016/j. nicl.2017.01.025

110. Casali AG, Gosseries O, Rosanova M, Boly M, Sarasso S, Casali KR, Casarotto S, Bruno MA, Laureys S, Tononi G, Massimini M (2013) A theoretically based index of consciousness independent of sensory processing and behavior. Sci Transl Med 5(198):198ra105. https://doi.org/10.1126/scitranslmed.3006294

111. Tononi G, Boly M, Massimini M, Koch C (2016) Integrated information theory: from consciousness to its physical substrate. Nat Rev Neurosci 17(7):450-461. https://doi.org/10.1038/ nrn.2016.44

112. Casarotto S, Comanducci A, Rosanova M, Sarasso S, Fecchio M, Napolitani M, Pigorini A, Casali G, Trimarchi PD, Boly M, Gosseries O, Bodart O, Curto F, Landi C, Mariotti M, Devalle G, Laureys S, Tononi G, Massimini M (2016) Stratification of unresponsive patients by an independently validated index of brain complexity. Ann Neurol 80(5):718-729. https://doi.org/10.1002/ ana. 24779

113. Bodart O, Gosseries O, Wannez S, Thibaut A, Annen J, Boly M, Rosanova M, Casali AG, Casarotto S, Tononi G, Massimini M, Laureys S (2017) Measures of metabolism and complexity in the brain of patients with disorders of consciousness. Neuroimage Clin 14:354-362. https://doi.org/10.1016/j.nicl.2017.02.002

114. Bai Y, Xia X, Kang J, Yin X, Yang Y, He J, Li X (2016) Evaluating the effect of repetitive transcranial magnetic stimulation on disorders of consciousness by using TMS-EEG. Front Neurosci 10:473. https://doi.org/10.3389/fnins.2016.00473

115. Giacino JT, Katz DI, Schiff ND, Whyte J, Ashman EJ, Ashwal S, Barbano R, Hammond FM, Laureys S, Ling GSF, NakaseRichardson R, Seel RT, Yablon S, Getchius TSD, Gronseth GS, Armstrong MJ (2018) Comprehensive systematic review update summary: disorders of consciousness: report of the guideline development, dissemination, and implementation subcommittee of the American Academy of Neurology; the American Congress of Rehabilitation Medicine; and the National Institute on Disability, Independent Living, and Rehabilitation Research. Neurology 91(10):461-470. https://doi.org/10.1212/WNL.0000000000 005928

116. Valente M, Placidi F, Oliveira A, Bigagli A, Morghen I, Proietti R, Gigli G (2002) Sleep organization pattern as a prognostic marker at the subacute stage of post-traumatic coma. Clin Neurophysiol 113(11):1798-1805

117. Babiloni C, Pistoia F, Sara M, Vecchio F, Buffo P, Conson M, Onorati P, Albertini G, Rossini PM (2010) Resting state eyesclosed cortical rhythms in patients with locked-in-syndrome: an EEG study. Clin Neurophysiol 121(11):1816-1824. https://doi. org/10.1016/j.clinph.2010.04.027 
118. Lee H, Golkowski D, Jordan D, Berger S, Ilg R, Lee J, Mashour GA, Lee U, Re CSG (2019) Relationship of critical dynamics, functional connectivity, and states of consciousness in large-scale human brain networks. Neuroimage 188:228-238. https://doi. org/10.1016/j.neuroimage.2018.12.011

119. Real RGL, Veser S, Erlbeck H, Risetti M, Vogel D, Muller F, Kotchoubey B, Mattia D, Kubler A (2016) Information processing in patients in vegetative and minimally conscious states. Clin Neurophysiol 127(2):1395-1402. https://doi.org/10.1016/j.clinp h.2015.07.020

120. Kempny AM, James L, Yelden K, Duport S, Farmer SF, Playford ED, Leff AP (2018) Patients with a severe prolonged disorder of consciousness can show classical EEG responses to their own name compared with others' names. Neuroimage Clin 19:311319. https://doi.org/10.1016/j.nicl.2018.04.027

121. Wu M, Li F, Wu Y, Zhang T, Gao J, Xu P, Luo B (2020) Impaired frontoparietal connectivity in traumatic individuals with disorders of consciousness: a dynamic brain network analysis. Aging Dis 11(2):301-314. https://doi.org/10.14336/AD.2019.0606

122. Li YQ, Pan JH, He YB, Wang F, Laureys S, Xie QY, Yu RH (2015) Detecting number processing and mental calculation in patients with disorders of consciousness using a hybrid braincomputer interface system. BMC Neurology 15(1):259. https:// doi.org/10.1186/s12883-015-0521-z(ARTN259)

123. Wang F, He Y, Qu J, Xie Q, Lin Q, Ni X, Chen Y, Yu R, Lin C-T, Li Y (2016) An audiovisual BCI system for assisting clinical communication assessment in patients with disorders of consciousness: a case study. In: 2016 38th Annual International Conference of the IEEE Engineering in Medicine and Biology Society (EMBC).. IEEE, pp 1536-1539

124. Faugeras F, Rohaut B, Weiss N, Bekinschtein TA, Galanaud D, Puybasset L, Bolgert F, Sergent C, Cohen L, Dehaene S, Naccache L (2011) Probing consciousness with event-related potentials in the vegetative state. Neurology 77(3):264-268. https:// doi.org/10.1212/WNL.0b013e3182217ee8

125. Formisano R, Toppi J, Risetti M, Aloisi M, Contrada M, Ciurli PM, Falletta Caravasso C, Luccichenti G, Astolfi L, Cincotti F, Mattia D (2019) Language-related brain potentials in patients with disorders of consciousness: a follow-up study to detect "covert" language disorders. Neurorehabil Neural Repair 33(7):513522. https://doi.org/10.1177/1545968319846123

126. Gosseries O, Sarasso S, Casarotto S, Boly M, Schnakers C, Napolitani M, Bruno MA, Ledoux D, Tshibanda JF, Massimini M, Laureys S, Rosanova M (2015) On the cerebral origin of EEG responses to TMS: insights from severe cortical lesions. Brain Stimul 8(1):142-149. https://doi.org/10.1016/j.brs.2014.10.008

127. Formaggio E, Cavinato M, Storti SF, Tonin P, Piccione F, Manganotti P (2016) Assessment of event-related EEG power after single-pulse TMS in unresponsive wakefulness syndrome and minimally conscious state patients. Brain Topogr 29(2):322-333. https://doi.org/10.1007/s10548-015-0461-3 